\title{
Devices for protecting bridge superstructures from pounding and unseating damages: an overview
}

\author{
Bipin Shrestha*; Hong $\mathrm{Hao}^{2}$; and Kaiming $\mathrm{Bi}^{3}$ \\ Center for Infrastructural Monitoring and Protection \\ Dept. of Civil Engineering, Curtin University, \\ Bentley, WA 6102, Australia.
}

*(bipinsh01@gmail.com, mailto:bipin.shrestha@postgrad.curtin.edu.au) 


\title{
Devices for protecting bridge superstructures from pounding and unseating damages: an overview
}

\begin{abstract}
Previous earthquakes have highlighted the seismic vulnerability of bridges due to excessive movements at expansion joints. This movement could lead to the catastrophic unseating failure if the provided seat width is inadequate. Moreover, seismic pounding is inevitable during a strong earthquake due to the limited gap size normally provided at the expansion joints. Various types of restrainers, dampers and other devices have been proposed to limit the joint movement or to accommodate the joint movement so that the damages caused by the excessive relative displacements could be mitigated. To select and design appropriate devices to mitigate the relative displacement induced damages on bridge structures during earthquake shaking, it is important that results from the previous studies are well understood. This paper presents an overview on the various pounding and unseating mitigation devices that have been proposed by various researchers. Based on an extensive review of up-to-date literatures, the merits and limitations of these devices are discussed.
\end{abstract}

Keyword: seismic pounding; unseating failure; bridge joints; restrainers; dampers.

\section{Introduction}

Bridges with multiple spans are often constructed with joints to accommodate temperature and time-dependent deformations. These joints act as physical cuts on the bridge superstructure. During the seismic events, poundings between the adjacent bridge components (deck to deck and/or deck to abutment) can occur when the relative closing displacement is larger than the expansion gap size. Pounding of adjacent bridge segments not only results in the localized damages around impacting locations but also could increase the relative opening movement between adjacent components of a bridge structure (Rungrasamme \& Kawashima, 2001). On the other hand, unseating failure occurs when the relative opening displacement is larger than the provided seat width. The damages related to pounding and unseating have been observed in many recent major earthquakes, e.g. the 2011 Christchurch earthquake (Chouw \& Hao, 2012), 2010 Chile earthquake (Kawashima, Unjoh, Hoshikuma, \& Kosa, 2011), 2008 Wenchuan earthquake (Lin, Hung, Lou, \& Chai, 2008), 2006 Yogyakarta earthquake (Elnashai 
, Kim, Yun, \& Sidarta, 2006), 1999 Chi-Chi earthquake (EERI, 1999), 1995 Kobe earthquake (Kawashima \& Unjoh, 1996) and 1994 Northridge earthquake (Hall, 1994).

Retrofitting of bridges to mitigate the damages resulting from strong earthquakes has become a common measure in many seismic prone regions. Caltrans initiated retrofitting of its bridges to prevent unseating failure after the devastating 1971 San Fernando earthquake in California. During this earthquake, many bridges with typical narrow seat width collapsed due to the excessive longitudinal movements at expansion joints and supports (Jennings, 1971). To prevent unseating of the bridge spans, the spans were tied together with restrainers, typically made of steel cables or steel rods, at their hinges after the earthquake. These traditional restrainers have many limitations, such as small elastic strain range, and limited ductility 'capacity. To address the limitation of these restrainers, significant numbers of researches were carried out in the following years. These researches led to the use of various types of new materials or the use of energy dissipating devices as the restrainers. These new restraining devices alleviated the limitation of the traditional restrainers to a certain extent. However, these new devices also have some limitations, such as high cost of material, less durability, sensitive to earthquake ground motion characteristics (velocity dependent behaviour), and sensitive to ambient temperature, etc.

This paper presents an overview of the devices that are proposed/used to mitigate the pounding and unseating damages on highway bridges. Up-to-date information on experimental and numerical works and present-state-of-practice on the devices used to mitigate the pounding and unseating failure of bridge superstructures are included in the review. The merits and limitations of these devices for practical applications on bridge structures are discussed and commented. The paper focuses on the devices that are applied externally to the bridge superstructure. The structural element built-in along the bridge structures, such as concrete shear keys, retainer blocks are not included in this paper.

\section{Restrainers}

\subsection{Steel Restrainers}

Steel cable/bar restrainers are the least expensive and the most widely adopted retrofit strategy to prevent unseating failure of bridge decks. The 1971 San Fernando earthquake revealed the vulnerability of typical bridges of that period to the unseating failures at hinges (Jenning, 1971). After the event, steel cable restrainers were extensively used in the USA to mitigate the 
unseating failure on bridges with narrow seat length. Additionally, the restrainers were also used in new bridges with adequate seat length as a secondary back-up member to prevent unseating failure.

A typical restrainer connection layout used in typical Californian multiple-frame bridges are presented in Figure 1. The typical restrainer cables used in California are $19 \mathrm{~mm}$ diameter (area $143 \mathrm{~mm}^{2}$ ) steel cables and $32 \mathrm{~mm}$ diameter (area $3217 \mathrm{~mm}^{2}$ ) high strength rods. The steel cables are made of 6x19 strands, galvanized with a wire strand core and have a yield strength of $174 \mathrm{kN}$ corresponding to the yield stress of $1210 \mathrm{MPa}$. The high strength steel rods have the yield stress of $827 \mathrm{MPa}$ and ultimate strength of $1034 \mathrm{MPa}$. The initial modulus of elasticity of the cables is $69 \mathrm{GPa}$, which is approximately $1 / 3$ of that of steel rods. The commonly used cable restrainers are $6.1 \mathrm{~m}$ long that can stretch approximately $107 \mathrm{~mm}$ at elastic limit and 267 $\mathrm{mm}$ at failure. The restrainers are designed to remain within the elastic range utilizing only the restrainer's spring-like ability while seismic energy is dissipated by the plastic hinging of the columns (Caltrans, 2008). These criteria make cables more practical than bars as the cables have a longer elastic range and thus, shorter restrainers can be used. The restrainers are threaded through a $150 \mathrm{~mm}$ diameter hole drilled on the top part of the hinge. Bolster are provided on one side of the hinge to distribute the restrainer force into the superstructure. The restrainer units are bolted to metal plates on the other side of the hinge. During installation, a slack of few millimetres is provided depending on the ambient temperature. This allows for thermal expansion without putting restrainers into tension. For steel/concrete simply supported bridge girders resting on a pier cap, a variety of restrainer configuration could be adopted to prevent unseating. If the bridge piers are strong enough, the restrainers can be wrapped around the girder and bent cap, as shown in Figure 2 (b) to provide additional restraint to the superstructure. Attaching restrainers from girder to girder (Figure 2 (a)) is preferable when the additional force applied by the restrainers to the bent cap may potentially damage the piers. In general, girder to girder attachment is less desirable because the girders are not directly attached to the pier on which they are seated. During a strong earthquake, flexible column may experience large deflections which may lead to unseating if the girders are not attached to the piers directly.

Typical Japanese bridge constructions do not use the flexible cable restrainers as in the USA. Instead, falling prevention devices are used, which do not allow the relative displacement between spans. These include devices that connect a girder and substructures (Figure 3 (a)), 
devices that protrude into a girder from bridge substructure (Figure 3 (b)), and device to connect two girders (Figure 3 (c)).

As mentioned above, steel restrainers were applied on many bridge structures in US after the 1971 San Fernando earthquake. The following major earthquakes, such as the 1989 Loma Prieta, the 1994 Northridge earthquakes and the 1995 Kobe earthquake provided good opportunities to evaluate the performance of these steel restrainers. Steel cable restrainers were found to be effective to prevent the span collapse. However, failures of restrainers were also observed in a few cases (e.g. Gavin Canyon under crossing), which resulted in the unseating of bridge decks. As the restrainers are designed to perform elastically, this tends to attract large forces during an extreme event resulting in either the breaking of the cable or punching of the diaphragm wall at ends of the restrainer (Selna, Malvar, \& Zelinski, 1989).

Figure 1. Hinge restrainer retrofit scheme.

Figure 2. (a) Girder to girder and (b) girder to column restrainer attachment for simply supported bridges.

Figure 3. Japanese displacement restriction devices.

To improve the effectiveness of the steel restraining devices, significant studies have been conducted. Saiidi, Maragakis, Abdel-Ghaffer, Feng, and O’Conner (1993) investigated the seismic responses of bridge structures retrofitted with cable restrainer during the 1989 Loma Prieta earthquake. Their study concluded that restrainers are affected by many factors such as the amplitude and frequency contents of the ground motion, soil-structure interaction as well as the flexibility of substructure and nonlinear time history analysis is necessary for appropriate design. Abdel-Ghaffer, Maragakis, and Saiidi (1997) studied the effects of the cable restrainers on the seismic response of the Aptos Creek bridge during the 1989 Loma Prieta earthquake and found that restrainer had little impact on the overall structural response. However, restrainers were found effective to reduce the displacement at joints at higher acceleration. A parametric study on the cable restrainer effect on pounding response of multi-frame bridges was conducted by DesRoches and Muthukumar (2002) using SDoF model. It was revealed that the effectiveness of restrainers depend highly upon the period ratio of adjacent structures. The addition of restrainers increased the displacement of stiff frames. The effects of restrainers on 
the frame responses were mainly observed only for highly out-of-phase frames (i.e. frames with stiffness ratio which is significantly lower than unity) and was marginal for other stiffness ratios. Vlassis, Maragakis, and Saiidi (2004) conducted a large scale experiment to evaluate the efficacy of restrainers in reducing relative displacement across bridge hinge, and to examine the effects of restrainer stiffness and gap on the response of the hinge-restrainer system. It was found that restrainers were capable of inhibiting the relative hinge displacement and generally capable of reducing the intensity of impact between two adjacent decks. The restrainer force and ductility demand increase when restrainer gap is zero, which could happen at low ambient temperatures, resulting in extensive yielding of restrainer even under moderate earthquake excitations. It could result in high stress concentration at the location where the cables pass around the two $90^{\circ}$ bends on the drum and could also result in failure of the restrainers.

Watanabe and Kawashima (2004) investigated on the effectiveness of cable restrainers to mitigate rotation of a skewed bridge during strong earthquake motions. Three configurations of cable restrainers were evaluated. In the first configuration restrainers were provided along the skewed longitudinal direction ( $x$ direction as shown in Figure 4), in the second configuration restrainers were provided along the Longitudinal direction ( $X$ direction) and in the final configuration restrainers were provided along the skewed transverse direction $(y$ direction). Julian, Hayashikawa, and Obata (2007) evaluated the efficiency of using cable restrainers to mitigate unseating damage on isolated curved steel viaducts. The restrainers were generally found to be effective on minimizing the pounding forces at the expansion joint and on reducing the joint opening movements. It was revealed that due to the tendency of curved bridge rotating about the vertical axis irregular distribution of restrainer stresses were developed. Restrainers located at the exterior girder of the curved bridges activated first and subjected to larger ductility demand.

Even though steel cable/bar restrainers had been used extensively in bridge retrofit, a satisfactory method for designing the restrainers was lacking. The old design codes (e.g. Caltrans 1990, AASHTO 1992) did not consider the relative displacement between the adjacent frames which is actually the reason behind the unseating of bridge spans. Researchers focused on this aspect and many design methods for seismic restrainers were proposed. Trochalakis, Eberhard, and Stanton (1997) modified the equivalent static procedure for the design of the restrainers based on their numerical study. DesRoches and Fenves (2000) proposed a method to design the restrainer by predicting the expansion joints opening through modal analysis of the two adjacent bridge frames. This method had the advantage of considering the dynamic 
characteristics and the inelastic behaviour of adjacent frames. The hinge displacements are estimated by combining the modal displacement using Complete Quadratic Combination (CQC). This method is adopted by the Caltrans to design the seismic restrainers in Californian bridges with multiple-frames (Caltrans, 2008). Caltrans (2008) also provides the guidelines for required properties of restrainer material. For simply supported bridges, BDA adopts the method proposed by Saiidi, Randall, Maragakis, and Isakovic (2001).

It is to be noted that out-of-phase vibrations between bridge segments are not only caused by different dynamic properties of adjacent structures, Spatially Varying Ground Motions (SVGM) along the different supports of bridge and Soil Structure Interaction (SSI) also results in the out-of-phase vibrations between the bridge segments. Relative displacements at hinges and the resulting pounding force and deformation of the restrainers are significantly affected by SVGM and SSI (Chouw \& Hao 2005, 2008, Li, Bi, Chouw, Butterworth and Hao, 2012, Shrestha, Hao, and Bi, 2015). However, most of the previous studies have neglected these sources of out-of-phase vibrations. The only study in the literature that proposes a restrainer design method considering spatial variation of ground motions is by Hudgings, Eberhard, and Stanton (1997). However, due the complexity involved in calculating the relative displacement induced by the spatial variation of ground motion and SSI, the method have not found extensive applications.

Figure 4. Skew bridge rotation due to incoherent response (after Watanabe and Kawashima 2004).

As mentioned above steel restrainers do not have significant energy dissipation capacity, since they are designed to remain elastic. This results in a large number of restrainers required to limit the joint movement to an acceptable range, particularly for high seismic loads (DesRoches \& Fenves, 2000). Restrainer systems with an excessive number of restrainers could induce large forces in other components of the bridge, such as bearings and columns. Additionally, the restrainer cables and bars have low yield strain of $1.75 \%$ and $0.2 \%$, respectively. The limited elastic strain capacity results in a long length of restrainers to limit the joint movement at extreme earthquake scenarios to fulfil the requirement of elastic performance. These limitations of the steel restrainer have driven many investigations to find suitable alternatives to replace the steel restrainers. 


\subsection{Shape Memory Alloy restrainer}

Shape Memory Alloys (SMA) are a unique metallic alloy which can undergo large deformations while reverting back to their undeformed shape through either the application of heat (shape memory effect) or the removal of the load (superelastic effect). These unique properties have led to the development of applications of SMAs in the biomedical field, aerospace field, and commercial industry. Recently, interests in the use of SMAs for seismic applications have also increased. The ability of SMAs to recover their shape is, in part, due to the ordered crystalline structure between the austenite and martensitic phases which allows the material to undergo a displacive martensitic phase transformation as a result of temperature change or applied stress (DesRoches, McCormick, \& Delemont, 2004). In the seismic application, the superelastic SMA has found a wide application due to its ability of recovering its shape without the application of heat (Shrestha \& Hao, 2015).

Superelastic SMA displays a flag-shape hysteresis under cyclic axial loading, which can provide both re-centering and supplemental energy dissipation. Total recovery of axial deformation can be obtained for strains up to $6-8 \%$ with partial recovery being obtained for higher strain levels (DesRoches \& Delemont, 2002). This large elastic strain along with the hysteretic damping and strain hardening at large strains make SMA a suitable alternative material for the use as seismic restrainers (Andrawes \& DesRoches, 2005).

Realizing the potential of SMA for application as a seismic restrainer, a significant number of researches have been carried out in the last few decades. DesRoches and Delemont (2002) conducted a series of cyclic test on a full-scale Nitinol (NiTi) SMA restrainer bar of length 280 $\mathrm{mm}$ and $25.4 \mathrm{~mm}$ diameter to investigate the mechanical properties of SMA restrainers. The study also investigated the effectiveness of the SMA restrainer bars in a multi-span simply supported bridge through nonlinear numerical analyses. The numerical results showed that SMA restrainers were extremely effective in limiting the response of bridge decks during strong ground motions. The strain hardening of SMA restrainers at strains beyond $6 \%$ increased the stiffness of the restrainers and provided additional restraint to limit the relative opening in the bridge.

Andrawes and DesRoches (2005) assessed the effectiveness of SMA restrainers on a typical Californian multiple-frame box girder bridge using numerical simulations. Superelastic NiTi 
restrainers were found significantly more effective than conventional steel restrainers to reduce the opening relative displacement. It was also found that the frame drifts were not significant different for two types of restrainers. Andrawes and DesRoches (2007a) conducted a comparative analysis of SMA tension only restrainer, and tension and compression restrainer with other bridge retrofit devices, such as steel cable restrainer, metallic dampers and viscoelastic dampers. The steel restrainer cables were found to be the least effective in limiting the joint displacement. The comparison between the SMA device and the metallic damper showed that superelastic behaviour of the SMA is of more significance in limiting the joint opening compared to the higher damping of metallic dampers. Comparison with viscoelastic damper showed that the SMA devices have significantly lower forces while providing similar limits on joint opening. Johnson, Padgett, Maragakia, DesRoches, and Saiidi (2008) conducted a large scale testing of NiTi SMA restrainers for retrofitting of the bridges. Padgett, DesRoches, and Ehlinger (2010) used SMA restrainer to connect the deck-abutment interface of the bridge. The performance of the device for limiting the hinge opening was evaluated on a large scale four span concrete slab bridge. Guo, Zhao, and Li (2012) conducted an experimental study to investigate the performance of SMA restrainers for mitigating the pounding and unseating of highway bridges. The experimental study was conducted for two connection schemes (deck to deck and pier to deck) with SMA restrainers.

One of the major drawbacks of SMA restrainers is their performance, which is dependent upon the ambient temperature. The superelasticity characteristics of SMA exhibited only at the temperatures above the austenite finish temperature. In applications where the superelastic behaviour is desired, the temperature of the SMA has to be kept above Austenite finishing temperature, otherwise the SMA will experience residual deformations. Andrawes and DesRoches (2007b) evaluate the performance of SMA seismic restrainers under the effect of varying ambient temperature. The results indicated that the SMA restrainers are more effective in limiting the hinge opening at higher ambient temperature. At $20^{\circ} \mathrm{F}\left(-6.7^{\circ} \mathrm{C}\right)$ an average increase in the joint opening of approximately $41.5 \%$ was observed for frames with moderate to high period ratio compared to that at $60^{\circ} \mathrm{F}\left(15.6^{\circ} \mathrm{C}\right)$. It is worth noting that one of the most used commercially nitinol SMA, NiTi45, have the lowest austenite finishing temperature of $10^{\circ} \mathrm{C}$ (Alam, Youssef, \& Nehdi, 2008). According to ASTM 709 bridge steel specification (2005), the lowest temperature (AASHTO Zone 3) in bridge application is set to $-51^{\circ} \mathrm{C}$. Therefore, the use of NiTi SMA as a restrainer is limited by the cold temperatures. 
To overcome the limitations of the NiTi SMA, investigators have proposed the CuAlBe alloys, which have the potential of providing both damping and re-centering properties. The most notable property of CuAlBe is its very wide operating temperature range from $-80^{\circ} \mathrm{C}$ to $100^{\circ}$ C. This property of CuAlBe alloys makes it a suitable restraining device for cold regions. Zhang, Hu, and Zhu (2009) conducted the experiments of superelastic CuAlBe alloy bars at various temperatures $\left(23,0,-25\right.$ and $\left.-50^{\circ} \mathrm{C}\right)$ and developed a model to describe the stress-strain behaviour under various temperature. The authors conducted a numerical simulation of isolated highway bridge with CuAlBe based SMA restrainers. It was found that the ambient temperature of $-25^{\circ} \mathrm{C}$ have only minor effect on the control performance of the SMA device for the most cases.

Besides the dependence on ambient temperature, NiTi SMA restrainers also have other shortcomings, such as expensive cost and difficulty of machining. These shortcomings could be adequately addressed by using copper based SMA, which are relatively cheaper and easier to machine.

\subsection{Fiber reinforced polymer restrainer}

The high tensile strength and versatility of Fiber-Reinforced Polymer (FRP) fabrics are the motivational properties that lead to the exploration of these materials as potential seismic restrainer (Saiidi, Johnson, \& Maragakis, 2006, Johnson, Saiidi, \& Maragakis, 2005). FRP restrainers offer advantages over steel restrainer with respect to the ease of fabrication and installation. FRP connection to the superstructures is done by applying adhesives onto the bridge deck whereas installation of conventional restrainers is intrusive, requiring drilling of concrete. There are additional savings by elimination of the cost of connecting hardware (Saiidi et al. 2006). Usually, the conventional restrainers are hidden at the interior of the box girder, making them hard to inspect, whereas FRP restrainers are visible.

Saiidi et al. (2006) developed the FRP restrainers and tested a representative bridge hinge model with restrainer on a shake table. The developed FRP restrainers consisted of three segments: two end parts that were bonded to the superstructure surfaces, and the middle part that linked the two adjacent bridge frames as shown in Figure 5. The middle part of FRP restrainers needs to be flexible to allow the initial slack to accommodate hinge opening due to the thermal movements and to deform out-of-plane without developing significant stresses 
during hinge closing. To allow this to happen, flexible silicon elastomer was used in the middle portion of the FRP restrainer. Three different types of restrainers, namely GFRP, CFRP and a hybrid restrainer made of glass and carbon fibres (CGFRP) were tested by the authors. During the testing, GFRP restrainer reached the maximum strain of 3.6\%, 1.4\% higher than the design strain. CFRP restrainer ruptured when it reached a strain of $1.7 \%, 0.5 \%$ higher than the specified design strain. CGFRP restrainer reached the maximum strain of $1.5 \%$.

Figure 5. Test setup for CFRP restrainer (after Johnson et al. 2005)

A comparison of the relative hinge movement for GFRP, steel and SMA restrainers were made to evaluate the performances of these restrainers. Figure 6 (a) and (b) presents the comparison of the relative hinge movement and superstructure acceleration with three types of restrainers. As presented in the figure, the maximum restrainer elongation (maximum hinge movement less the restrainer slack) for the SMA and FRP restrainers was $22.9 \mathrm{~mm}$ and $4.2 \mathrm{~mm}$, respectively. The steel restrainer failed at $\mathrm{t} \approx 14.7 \mathrm{sec}$ after it stretched by $105 \mathrm{~mm}$. During the test run the peak superstructure acceleration was 4.97, 2.97, and $2.23 \mathrm{~g}$ for steel, SMA and GRRP restrainers, respectively.

The authors also developed a new design method for the FRP seismic restrainers. The basic assumption in the proposed method is that the FRP restrainers rigidly connect the two adjacent segments of the bridge. The linkage of the two bridge frames reduces the two-degree-offreedom system of the bridge frames to an SDoF system. The restrainers were assumed to link the two frames into an SDoF with a combined mass of $\mathrm{M}=\mathrm{M} 1+\mathrm{M} 2$ and stiffness of $\mathrm{K}=$ $\mathrm{K} 1+\mathrm{K} 2$.

Figure 6. Comparison of hinge movement (a); superstructure acceleration for different restrainer types (after Johnson et al. 2005)

It is to note that FRP restrainers suffer from similar deficiency as the steel restrainers since the performance of FRP are also governed by the linear response.

\section{Damping devices}




\subsection{Metallic dampers}

Metallic dampers are considered to be one of the most effective energy dissipating devices (Soong \& Dargush, 1997). They are essentially displacement dependent energy dissipating devices which dissipate energy through the yielding of the metallic material. These devices typically exhibit hysteretic force-displacement behaviour, which can approximate as bilinear or trilinear curve. Metallic dampers could be used in the form of rectangular or circular tubes or bars. Alternatively, steel shear panels can also be used to function as a yielding damper. These devices tend to be inexpensive to produce, and their properties remain stable over the long periods. However, they often need replacement after a large seismic event. In continuous bridge, they may be located either in one position to allow free movement of the bridge or distributed in several locations to allow thermal movements of the structure. Figure 7 shows typical metallic yielding dampers installed in Chilean highway bridges (Elnashai et al., 2010).

Chen, Bothe, \& Ger (2001) conducted extensive testing of metallic dampers on a 1:10 scale bridge model to reduce the dynamic response of the bridge structure. Their study focused on optimizing the metallic dampers for maximum energy dissipation and identifying the response of bridge model with dampers. Three full-scale dampers, two straight and one linearly tapered rods were fabricated and tested under cyclic loading. It was found that at the same applied load, the damper with tapered shape experienced large displacement thus more energy dissipation. Andrawes and DesRoches (2007) revealed that metallic dampers were capable of dissipating significantly more energy than other devices. Vasseghi (2011) and Pan, Yan, Wang, Xu, and Xie (2014) proposed metallic yielding devices to improve the seismic performance and prevent the pounding between the superstructures and concrete shear keys under transverse seismic excitation. The energy dissipating shear keys transfer a fraction of the seismic load to the substructures and dissipate the seismic energy through inelastic deformations. Four full-scale specimens were tested under cyclic loading, good ductility and energy dissipation capacity of the device were observed. Furthermore, nonlinear time history response of a three span precast concrete girder bridge with proposed shear key indicates that seismic demands on the substructures are reduced when conventional concrete shear key were replaced by the proposed shear key. Deng, Pan, Su, Ran, and Xue (2014) proposed a novel energy dissipation restrainer using steel shear panels to avoid bridge superstructure dislocation/unseating during a seismic event. Figure 8 shows the schematic application of such devices at bridge superstructure. To evaluate the performance of the steel shear panel devices and to identify its hysteretic behaviour, five damper specimens were designed and tested using cyclic loading. The test 
result suggested that with proper design, the devices were capable of large deformation and energy dissipation. The authors used finite element model to supplement their experimental study. Based on the numerical results, a design procedure for the device was formulated along with a suggestion for the sizes of stiffener and flanges of the device for the stable performance.

A drawback of these kinds of devices is they depend upon the hysteretic response of metal for the dissipation of seismic energy. Though, the dampers have good seismic energy dissipating capacity it also result in the residual deformation in the dampers. Thus, the devices may need to be replaced after a strong earthquake. Alternatively, this residual deformation could also result in the residual deformation in bridge superstructures that could influence the traffic flow immediately after the earthquake. To resolve these problems, Choi, Lee, and Choei (2009) carried out investigations on the application of superelastic SMA bending bars. The superelastic SMA bending bars were upgraded version of SMA bar/cable restrainers that activate only in tension and do not resist compressive force. The authors analysed the characteristic of the bending behaviour of the SMA bar and investigated its effectiveness for the seismic application. The superelastic SMA under single and double bending was tested under a quasi-static loading. Figure 9 presents the test setup for the single bending test of SMA bars. The average damping ratio of the SMA bending bars were found to be just below $7 \%$, which is slightly lower than that of metallic dampers that have damping ratio of around $10 \%$ (Chen et al., 2001). The bending behaviour of the SMA bar was not affected by the loading rate, which is different from its behaviour under tension. The SMA bars were assessed as seismic restrainer for a three-span simply-supported bridge. The bars reduced the joint openings and pounding forces at intermediate hinges and abutments. Choi, Park, Yoon, Choi, and Park (2010) compared the seismic performances of bridge with SMA bending bar restrainers with the conventional steel restrainers and SMA bars in tension only. The fragility analysis revealed that SMA bars in bending were the most effective in improving the seismic resistance of the bridge. The other two restrainers increased the bridge fragility of the as-built bridge under slight and moderate damages and slightly reduced the seismic resistance for the extensive and complete damages. However, the SMA bars not only reduce the fragility under all performance levels but also significantly improved the performance for extensive and complete damages. 
Figure 7. Metallic yielding dampers on Chilean bridges (after Elnashai et al. 2010)

Figure 8. Installation of the device (after Deng et al. 2014)

Figure 9. Test setup for SMA bar under single bending; (a) a ball and a cylinder; (b) a ball bolted to the SMA bar and the cylinder welded at the bottom; (c) bending shape of SMA bar under single bending (after Choi et al. 2009)

\subsection{Viscoelastic dampers}

Viscoelastic (VE) dampers belong to the family of the velocity dependent energy dissipating devices. The viscoelastic dampers, typically used for the structural applications, are made of copolymers or elastomeric substances, as presented in Figure 10. Energy is dissipated when they are subjected to shear deformation. Viscoelastic dampers consist of layers of the viscoelastic material sandwiched between steel layers. The mechanical behaviour of the damper is frequency dependent. The stress-strain relationships of the VE dampers are characterized by an ellipse with a non-zero slope. The slope of the ellipse is controlled by the shear stiffness of the VE materials while the area of the ellipse is controlled by the shearing rate. The response can be regarded as the summation of a linear elastic component and a viscous (elliptical) component.

The elastic stiffness can be related with the viscous damping through the following equation

$$
C_{d}=K_{d} \frac{\eta}{\omega}
$$

where $C_{d}$ is the damping coefficient, $K_{d}$ is the elastic stiffness, and $\eta$ is the loss factor. Many previous researches (e.g. Soong \& Dargush, 1997) have found that $\eta$ is almost a constant at various frequency values.

Feng, Kim, and Shinozuka (2000) and Kim, Feng, and Shinozuka (2000) studied the effect of using viscoelastic dampers at the expansion joints of highway bridges to prevent the unseating of superstructures off their seats and pounding of decks during earthquakes. Finite element analyses were performed using Kelvin model (consists of an elastic spring and a viscous damper connected in parallel) and Maxwell model (consists of an elastic spring and a viscous 
damper connected in series) for the viscoelastic dampers. The outcome of this research illustrated that using viscoelastic dampers reduces hinge openings without introducing a significant increase in the ductility demand in bridge piers. These investigations also revealed that viscous material component of a viscoelastic damper were significantly more effective in reducing the relative displacement at the bridge expansion joints than the elastic spring component.

Figure 10. Typical viscoelastic Dampers.

Andrawes and DesRoches (2007) compared the viscoelastic dampers with other bridge retrofit devices used to restrain the joint opening. It was found that the viscoelastic dampers are effective in reducing the joint opening and enhancing the re-centering capacity after the earthquake. However, force induced in the viscoelastic dampers are directly related to the frequency (relative velocity) of the joint opening rather than the joint opening displacement. Therefore, it may be very hard to control and design for specific force level.

It is worth mentioning that increase in temperature, due to cycling of the damper, can significantly reduce the storage and loss moduli, which in turn can result in the reduced stiffness and energy dissipation capacity of the damper (Chang, Soong, Lai, \& Nielsen, 1993; Kanitkar, Aiken, Nishimoto, \& Kasai, 2006). The viscoelastic dampers also have the disadvantages of limited deformation capacity and plausible deboning and tearing of viscoelastic material (Symans et al. 2008).

\subsection{Fluid viscous dampers}

Fluid viscous dampers are commonly used as passive energy dissipation devices for seismic protection of structures. Such dampers consist of a hollow cylinder filled with fluid. The fluid is typically silicone based. As the damper piston rod and piston head are stroked, fluid is forced to flow through orifices either around or through the piston head. The resulting differential pressure across the piston head can produce very large forces that resist the relative motion of the damper. The fluid flows at high velocities, resulting in the development of friction between fluid particles and the piston head. The friction forces give rise to energy dissipation in the form of heat. The associated temperature increase can be significant, particularly when the damper is subjected to long-duration or large-amplitude motions (Makris, Roussos, Whittaker, \& Kelly, 1998). The force generated by the device can be described as 


$$
P(t)=C|\dot{u}(t)|^{\alpha} \operatorname{sign}[\dot{u}(t)]
$$

where $P(t)$ is the force applied to the piston, $\dot{u}(t)$ is the piston velocity, $\mathrm{C}$ and $\alpha$ are constants depending on the fluid properties; $\alpha$ may range from 0.1 to 2 , according to the type of valves. Force-displacement relations for devices with different values of $\alpha$ subjected to sinusoidal input are elliptical shaped. Force-velocity curves for different values of $\alpha$ are illustrated in Figure 11.

$\alpha$ with low values are preferred in the case where high energy dissipation per cycle is required. On the other hand, $\alpha$ with high value (e.g. 2) is preferred when the difference of force at low and high velocities shall be maximized, in order to react stiffly as soon as the velocity increases, while allowing slow movements due to thermal variations, creep and shrinkage, and becoming rigid in case of dynamic actions (braking force and earthquake), or when energy dissipation is not required. In this case they are normally named as Shock Transmission Units (STU). An example of an application of STU in bridges is presented in Figure 12.

Jankowski, Wilde, and Fujino (2000) conducted experimental and numerical investigations on the STU to mitigate pounding response of base-isolated bridge. The results of the experiment suggest that for the modelling purposes of STU under service loads caused by thermal, creep and shrinkage events, which result in slow movements, the Influence of the device can be neglected. On the other hand, the STU performed with high stiffness during earthquakes, which cause vibrations with a band of frequencies higher than $0.1 \mathrm{~Hz}$. For the numerical investigation, the authors modelled the STU using linear gap hook element. The STU acted as a link with very high stiffness during seismic events thus mitigating the pounding effects as well as limiting the moments on the piers.

Shinozuka, Feng, Kim, Nagashima, and Kim (2000) proposed retrofitting bridge structures using fluid viscous dampers in the form of dynamic restrainers. The authors evaluated the effectiveness of fluid viscous dampers with the damping exponent of 0.3 at the expansion joint of highway bridges. Through the extensive nonlinear analyses, it was found that the nonlinear dampers were very effective in limiting the relative opening displacements at expansion joints and pounding forces. The ductility demands in the substructures can also be suppressed by installing the viscous dampers at the expansion joints and both abutments. Strandgaard (2000) reported the first application of such dampers on a bridge structure with a length of 1270 foot 
(387 m) to absorb energy induced by earthquakes. The bridge was fitted with three fluid viscous dampers with capacity of 160 Kips (72.6 tonnes) and damping exponent of 0.4. It was found that with the application, it was able to reduce the seismic movement by approximately $45 \%$ and allow the use of smaller joint seal.

Figure 11. (a) Force-velocity relation for dampers with varying value of $\alpha$, (b) Hysteresis loop of a viscous damper for different value of $\alpha$

Figure 12. Shock transmission unit installed in a bridge.

One of the noteworthy limitations of these devices is that it requires regular inspection of fluid seal that are liable to leakage (Symans et al. 2008). Usually the inspections are recommended to be carried out in an interval of few years.

\subsection{Magneto rheological dampers}

The Magneto rheological (MR) dampers are a semi-active device containing MR fluid. MR fluid is composed of oil and varying percentages of iron particles that have been coated with an anti-coagulant material. When inactive, MR fluid behaves as ordinary oil but when exposed to a magnetic field, micron-size iron particles that are dispersed throughout the fluid align themselves along magnetic flux lines. Once this alignment is achieved, the iron particles resist being moved out of their respective flux lines and act as a barrier to fluid flow. Upon exposure to magnetic field, the MR fluid as a whole will appear to undergo a change in viscosity. The resistance caused by the iron particles on movement is what allows MR fluid to be applied in electrically controlled viscous dampers. A section view of a typical mono-tube MR damper is presented in Figure 13.

Recently many researchers have investigated the effectiveness of MR dampers to mitigate seismic induced poundings of bridge structures. Ruangrassamee and Kawashima (2003) studied the effectiveness of variable dampers in improving the structural seismic performance considering pounding effects of the highway bridges, in which the effectiveness of the frictiontype damping force scheme and the two-step viscous damping force scheme were analysed. The authors observed that the damping force in the two-step viscous damping force scheme was much smoother than that in the friction-type damping force scheme. The force of the friction-type damping scheme changes when the sign of velocity of the damper changes. The 
sudden changes of the damping force may cause shocks in the devices. Nonetheless, both the damping schemes were effective in reducing the seismic responses including the pounding forces and pulse-like acceleration responses in the bridge joint. The friction-type damping force scheme with total damping force of $32 \%$ of the deck weight was found to be most effective in reducing the deck displacement, flexural hysteretic curvature at the plastic hinge locations and acceleration pulses at joint.

Figure 13. Mono-tube MR damper section view

Guo and Li (2008) investigated the possibility of using MR dampers to reduce the pounding effect on adjacent segments of highway bridges in extreme earthquake events. MR dampers were designed to trace the instantaneous optimal control forces for manipulating the dampers. The damper control algorithm was then modified to incorporate the time-delay effect of the control system based on predictive control algorithm. Two types of installation scheme were analysed by the authors, as presented in Figure 14. The first installation linked two adjacent superstructures and the second installation linked the superstructure with the substructure. The authors showed that semi-active control system can effectively reduce the structural acceleration response caused by pounding. Analyses also indicated that the time delay of the semi-active control system significantly deteriorates the performance of the control system. $\mathrm{Li}$ and Yue (2006) analysed the effectiveness of using MR dampers to control pounding response in elevated bridge. It was found that installing MR dampers between deck and piers will have much better performance than installing it between adjacent decks, and the relative displacement and bearing deformation decreases remarkably by applying a semi-active control device.

Figure 14. The installation schemes of the control devices (after Guo \& Li, 2008)

Guo, Li, Li, and Ou (2009) carried out both analytical and experimental investigations on a 1:20 scaled base-isolated two-span simply supported bridge model. A series of shake table tests were performed to investigate the effects of pounding between adjacent superstructures. Furthermore, the experiments were carried out with MR dampers to identify the effectiveness of the dampers to mitigate bridge vibration. The bridge model with the MR dampers was experimentally compared for three control systems (passive-off, passive on and semi-active control). It was found that with the passive off MR dampers, the pounding of the bridge segments could be suppressed. However, pounding still occurred during an earthquake due to the low energy dissipation. In the case of passive-on damper, poundings between the bridge 
segments were effectively reduced but pounding still occurred. The semi-active control system was effective in reducing the bridge response and was able to eliminate pounding incidences. Sheikh, Xiong, and Li (2012) investigated the effectiveness of different control strategies (passive off, passive-on and bang-bang control) of MR dampers to mitigate the pounding effect of base-isolated highway bridges. The authors conducted seismic response analysis of a threesegment bridge susceptible to pounding at the joints during an earthquake. It was revealed that all three control strategies are able to reduce the pounding responses.

The afore-mentioned researches have shown that semi-active control strategies of MR damper could be most effective in mitigating pounding and unseating damages. It is important to note that semi-active control requires external power source albeit small. Moreover, the performance of semi-active MR damper is also significantly depended upon the response delay time. The control algorithm is also rather complicated, which makes it difficult for general use in civil engineering applications.

\section{Modular expansion joints}

A Modular Expansion Joint (MEJ) system allows a large relative displacement between the bridge girders without compromising the bridge's serviceability and functionality. Using MEJs, it is possible to make the gap sufficiently large to cope with the largest expected closing girder movement, and consequently completely preclude pounding between adjacent girders and between girder and abutment. Originally, MEJ was developed to accommodate large thermal expansion and contraction of long bridges. Recently, investigators have focused on application of this device to mitigate relative displacement induced damages at bridge joints caused by seismic movement.

The cross section of the main components of an MEJ is presented in Figure 15. The bridge girders are joined by an edge beam at each girder end and by several centre beams. Seals cover the gaps between the beams and ensure the watertightness of the joint. The traffic load on the centre beams is transmitted to the supporting bar via yokes. Sliding springs, bearings and yokes of the system ensure the beams move uniformly and enable the adjoined bridge girders to accommodate expected relative movements of the bridge. The MEJs are provided with a fuse box system, which permits the expansion joint to break out at one side of the connection to the bridge girder. The fuse box prevents the expansion joints being damaged when unexpectedly 
large closing movement occurs and settle afterwards in such a way as to allow emergency vehicles to travel across the joint.

Figure 15. Section view of modular expansion joint

Chouw and Hao (2008b) propose the use of MEJ to mitigate the pounding between the adjacent structures. The authors studied the minimum gap width that MEJs have to accommodate between two bridge frames to prevent pounding when subjected to SVGM and SSI. It was found that using MEJ with a large gap, pounding between the adjacent frames could be completely precluded, thus preventing any localized damage at bridge girder. However, a large girder movement results in a large bending moment in bridge pier, which compensates the advantages of using MEJ in bridges to resist earthquake loading. Chouw and Hao (2009) further presented the minimum opening and closing movement required by MEJ to preclude the pounding. Bi, Hao, and Chouw $(2010,2011)$ using stochastic method calculated the required separation distances between abutment and deck and between two decks to avoid pounding in a bridge structure subjected to SVGM and SSI.

McCarthy, Wright, Padgett, DesRoches, and Bradford (2014) developed an analytical model to represent a common MEJ including its critical component, such as friction element, equidistant devices, support bars and centre beam and validated the model through full-scale experimental testing of the joint. To mitigate the damages to the MEJ due to the seismic events, Padgett and DesRoches (2013) developed a new shape memory alloy enhanced MEJ that can accommodate the heightened demands imposed during extreme events like earthquakes. The commonly used MEJ was enhanced by supplementing its equidistant system with SMA spring designed to supply additional displacement capacity during a seismic event while avoiding additional load transfer in the system that may damage other components. Yang and DesRoches (2015) developed a MEJ with innovative buckling resistant SMA. The buckling resistant SMA can provide a much higher recentering strength than unconfined SMA, which significantly reduces the amount of SMA and thereby the cost of the smart MEJ system. 


\section{Shock absorbing device}

Pounding of two adjacent bridge components (deck to deck or deck to abutment) results in an exchange of momentum and large acceleration pulses. It is also worthy to note that impact do not necessarily result in the contact between entire surfaces of contacting components. Due to the eccentric motions of bridge decks, it is observed that poundings more likely occur at the corners of the bridge decks. Large impact forces concentrated on the smaller area of the bridge deck and abutment could result in the localized damages such as crushing and spalling of concrete around impacting locations. Inserting a thin layer of a soft elastic material as shock absorbing devices between the impacting surfaces helps to alleviate the arbitrary eccentric contact (Leibovich, Rutenberg, \& Yankelevsky, 2012). Shock absorbing devices such as natural rubbers, metallic honeycomb devices can be used as a layer of soft materials to mitigate large acceleration pulses and to limit the localized damage on the impact surface of the adjacent bridge components.

Kitahara, Kajita, Nishimoto, \& Katsuki (2005) and Kajita, Kitahara, Nishimoto, \& Otsuka (2006) carried out a collision test between two steel solid bars in order to investigate the impact behaviour of the natural rubber bumpers. The test setup is presented in Figure 16. Natural rubber bumpers with the hardness of 50 (JIS K 6301) was used for the experiment. The results revealed that the relationship between the collision velocity and the maximum deformation of the rubber bumpers can be approximated by using the linear curve. The relationship between the collision velocity and the maximum impact force, on the other hand, resembled a parabolic curve. The authors suggested that the maximum impact force depends strongly on the collision velocity and the thickness of the natural rubber. Therefore, the collision velocity could be used as a design variable for the rubber bumpers. The authors also conducted a numerical simulation of the impact behaviour of rubber bumper using a general-purpose finite element code LSDYNA, which specializes in dynamic structural crush analysis. The natural rubber bumper is discretised into a cube of $1 \mathrm{~mm}$ size using 8-node solid elements sandwich between the rigid plates. The constitutive law of the natural rubber bumper was modelled using the Ogden's Law as

$$
W=\sum_{n=1}^{2} \frac{\mu_{n}}{\alpha_{n}}\left(\lambda_{1}^{\alpha_{n}}+\lambda_{2}^{\alpha_{n}}+\lambda_{3}^{\alpha_{n}}-3\right)
$$

where $\lambda_{i}$ is the elongation ratio of $\mathrm{i}$-direction, $\mu_{n}$ and $\alpha_{n}$ are material constants that are determined from the nominal stress-nominal strain curve of the natural rubber. 
The numerical model was used to simulate the static and the dynamic behaviour of the rubber bumper. However, the numerical analysis terminated when the compressive strain exceeds 0.6 due to tangling of finite elements. Collision simulation of rubber bumpers without the consideration of strain rate effect showed very poor match with the experimental results. Therefore, as presented in Figure 17, the strain rate effects have significant influence on the behaviour of rubber bumpers.

Figure 16. Test setup for the collision test of rubber bumper (after Kajita et. al. 2006)

Figure 17. Load vs Deformation curve with and without consideration of strain rate effect at $\mathrm{v}=0.34 \mathrm{~m} / \mathrm{s}$ (left); and $\mathrm{v}=0.68 \mathrm{~m} / \mathrm{s}$ (right) (after Kajita et. al. 2006)

Leibovich et al. (2012) investigated the pounding response of concrete rods with and without softer filling materials at the joint between the impacting concrete surfaces. Concrete rods with diameter of $100 \mathrm{~mm}$ and length of $500 \mathrm{~mm}$ and $1000 \mathrm{~mm}$ were used in the test. The experimental setup is shown in Figure 18. Two guide rails were added on each side of the rods to limit the eccentric pounding between the rods. However, during the test it was found that the guide rails were not able to fully eliminate the eccentric poundings. A typical time history of the acceleration records during an impact is shown in Figure 19 (a). The acceleration signals due to the impact and its propagation along the length of the piles could be seen in the figure. It is evident in the figure that the main impact signal is followed by several lower magnitude high-frequency vibration waves that damped out within 3-4 cycles. These waves mentioned as noises by the authors, could in fact be the stress wave resulting from the axial compression of the material at the impacting surfaces. It could also be noted that spike generated at target impacting face (sensor $\mathrm{J}$ ) travelled to the middle or the rod (sensor F), which is approximately $500 \mathrm{~mm}$ from the impacting face. From the figure, the travel time of the spike from the impacting face to the target CM can be calculated approximately to be $0.2 \mathrm{msec}$. Upon dividing the distance by the travel time, the velocity of propagation of the compressive wave could be obtained as approximately $2500 \mathrm{~m} / \mathrm{s}$. For a straight, prismatic, free-ended rod with length L, the fundamental period of axial vibration, T can be given by (Malhotra, Huang, \& Shakal, 1995, Clough \& Penzien, 1993) 


$$
T=\frac{2 L}{C}
$$

where $\mathrm{L}$ is the length of the concrete rod and $\mathrm{c}$ is the velocity of compressive wave. Substituting $\mathrm{L}=1 \mathrm{~m}$ and $\mathrm{c}=2500 \mathrm{~m} / \mathrm{s}$ into the eqn. $4, \mathrm{~T}=0.8 \mathrm{msec}$ could be obtained which approximately matches the period of vibration waves following the main spike. Thus, the waves following the main impact spike are actually caused by the impact stress waves.

The acceleration pulse resulting from the impact of two solid surfaces could be eliminated by the introduction of soft materials between the surfaces. Leibovich et al. (2012) used white sponge that is characterized by a very low modulus of elasticity glued to target specimen impacting face to mitigate the contact pressure and acceleration due to the impact. The sponge also helps to overcome the surface irregularities that are responsible for partial contact and provide full contact between the piles on impact. Figure 19 (b) shows the peak acceleration at the target impacting face $(\mathrm{J})$. As presented in the figure, a significant reduction the magnitude of the impact acceleration at the impacting face was observed. It could also be noted that the waves following the main impact during the impact test without any infill sponges were completely eliminated during the test with infill sponges. The result of the experiment prove that infill soft materials such as white sponge used in the test could not only reduce the large acceleration pulse but also completely eliminate the stress waves that are caused by the compression of the materials of the impacting elements. The softer infill material with low axial stiffness absorbs the high-frequency compressional waves, thus resulting in an elimination of high-frequency waves during an impact. However, as could be observed in Figure 19 (b), the duration of the impact is prolonged.

Figure 18. Experimental setup for impact test (after Leibovich et. al. 2012)

Figure 19. Acceleration record of concrete pile impact (a) without shock absorbing device, (b) with shock absorbing device (after Leibovich et. al. 2012)

Jankowski et al. (2000) investigated the effectiveness of rubber bumper and crushable devices to reduce the responses resulting from pounding of adjacent isolated bridge deck. The authors modelled the behaviour of rubber bumper using linear spring-dashpot elements. The stiffness and damping of a rubber bumper were calculated as follows 


$$
\begin{gathered}
k_{p}=\frac{E_{r} A_{p}}{t_{p}} \\
c_{p}=2 \xi \sqrt{k_{p} \frac{m_{s}}{2}}
\end{gathered}
$$

where $A_{p}$ is cross-sectional area of the rubber pad, $t_{p}$ is its thickness and $E_{r}$ is the Young modulus of rubber. $\xi_{r}$ is damping ratio of the rubber and $m_{s}$ is a mass of the superstructure segment. Two gap elements were modelled in series, the first to model the activation of rubber bumper when the gap between the bumper and bridge deck is closed. While the second gap element was placed with gap width equal to the separation between two bridge decks, to model the closing of the gap after full compression of rubber bumper.

The authors also investigated the crushable devices that were designed to be crushed by compression, giving sufficient space for deck to move and absorb the energy at the same time. Under the normal conditions such devices allowed the transmission of vehicle over them. During the severe earthquakes the devices get destructed due to the crushing, allowing the superstructure segments to vibrate independently and the device could be replaced after an event. The authors concluded that using hard rubber bumper leads to reduction of reaction forces (bending moment) of piers and also could significantly reduce the pounding force. However, due to the earlier activation of bumpers contact period gets lengthened but maximum forces of collisions are reduced. The dissipation of energy due to the plastic deformation of crushable devices were not found to be great effectiveness, however, the benefits were derived from unrestrained vibration of superstructure segments after crushing of the devices.

Kawashima and Shoji (2000) numerically investigated the effectiveness of steel restrainers with rubber Shock Absorbing Devices (SAD) to mitigate pounding between adjacent bridge decks. Three types of rubber bumpers with strain-hardening, strain-softening and elastic type hysteretic behaviour were investigated in the study. The study found that rubber SADs were effective in mitigating the impact forces as well as the acceleration impulse caused by pounding. The strain-softening devices were found to be more effective in reducing the impact indentation between the two decks with smaller compression force. Abdel Raheem (2009) investigated the effects of natural rubber pads on the isolated bridge structure. Rubber bumpers were modelled using exponential elastic impact element, without considering any impact 
damping. It was found that the rubber shock absorbers placed between the bridge segments significantly reduced the peak pounding force and the cable restrainers force was also reduced by rubber pad placed at the end of the restrainers. The author also suggested that rubber shock absorbing device with a half-gap slack size provides an economical and effective design that can reduce the impact force and acceleration response. Shrestha, Hao, and Bi (2014) evaluated the effectiveness of using rubber bumpers and restrainers to mitigate pounding and unseating damages on multiple-frame bridges subjected to SVGM. In this study, the rubber bumpers were modelled by using the nonlinear strain hardening model proposed by Kawashima and Shoji (2000) without any damping.

Though the rubber bumper is effective to mitigate the pounding response, impact models capable of representing the behaviour of rubber bumpers with sufficient accuracy are scarce. The researchers as mentioned above used the simplified model to represent the behaviour of the rubber bumper. A linear model with viscoelastic damping or nonlinear spring with no energy dissipation was normally adopted. To overcome this limitation, a new nonlinear inelastic force-based impact model, able to appropriately describe the behaviour of rubber under impact loading taking into account the limited thickness of the bumper was developed (Polycarpou, Komodromos, \& Polycarpou, 2013a, Polycarpou \& Komodromos 2013b). A simple and efficient nonlinear impact model with hysteretic damping for rubber bumpers was proposed and verified based on the experimental study by Kajita et al. (2006). As presented in Figure 20, the results obtained from the numerical analysis were very well correlated with the corresponding experimental data. The impact model was quite robust and it did not show instability problems at higher strains as those observed in LS-DYNA models by Kajita et al. (2006).

Though rubber bumpers are effective in reducing the pounding response of bridge structures, natural rubber is less durable to environmental loading. To overcome the durability problem Li, Mao, Li, and Zhao (2011) recently developed a novel shock absorber device-Shape Memory Alloy Pseudo Rubber (SMAPR). The energy dissipating and residual deformation selfrecovery ability of the device was achieved by using the martensitic NiTi SMAPR. The mechanical properties, self-recovery ability of SMAPRs and recovery of SMAPRs on heating were investigated to identify its potential as shock absorbing device for impact applications. The mechanical properties of the SMAPR specimens under cyclic compression loading were experimentally investigated under a controlled temperature. Sinusoidal cyclic compression 
load was applied along the stamping and moulding directions of the specimens. It was observed that the tangent modulus of SMAPR increased dramatically when the strain was larger than $20 \%$. It was found that the stress-strain curves are independent of the loading frequencies as the elastic force of the micro-spring, and the internal Coulomb friction force are not affected by the loading rate. Figure 21 (a) shows the deformation of a specimen before and after compression to a strain of 45\%. Figure 21 (b) shows the stress-strain curves of SMAPR specimens compressed to $30 \%, 40 \%$ and $48 \%$ strain amplitude. It is observable in the figure that no residual deformation was observed for $40 \%$ strain while $6 \%$ residual strain was found for the strain amplitude of $48 \%$. Therefore, the fully restorable residual strain limit of SMAPR was somewhere between $40 \%$ and $48 \%$.

Meng, Zhang, and Zhao (2011) conducted a shake table testing of high-pier bridge model to evaluate the efficacy of SMAPR to reduce seismic pounding in high-pier long-span bridges. Li, Guo, Cui, Mao, and Li (2015) investigated the mitigation mechanism of SMAPR on a scaled model (1:30) of an isolated bridge with two deck segment. In the bridge models, R15 $\alpha$ Acoustic Emission (AE) sensors were installed at the typical locations to capture the stress waves. The comparison of acceleration histories with and without the SMAPR shock absorbing devices showed that SMAPR not only significantly reduced the amplitude of impact but also eliminated the stress waves resulting from the impact.

Figure 20. Comparison between experimental and numerical force-displacement diagrams of a $10 \mathrm{~mm}$ thick rubber shock absorber for static and dynamic tests (after Polycarpou \& Komodromos, 2013a)

Figure 21. Self-restorable strain for SMAPR specimen (after Li et al. 2011)

\section{Hybrid devices}

In order to prevent unseating and pounding damages in the bridge structures, many researchers have investigated on the application of combination of devices to achieve the optimum protection. These devices complement each other to suppress the responses that may lead to the damage or failure of structures. 
One of such hybrid device that has been widely used is the combination of rubber bumpers along with restrainers. The restrainers prevent the unseating failure but have limited effect on pounding impacts while rubber bumpers as presented earlier have superior performance in mitigating pounding impact and stress wave resulting from the pounding. Kawashima and Shoji (2000) revealed that the rubber bumper along with restrainers at the bridge joint were not only effective in reducing joint acceleration and relative joint displacements but also reduce the response of bridge piers to some extent. Zhu, Abe, and Fujino (2004) proposed applying shock absorbing devices along with restrainers to counter pounding effects and to improve the serviceability of elevated bridges during a seismic event. Abdel Raheem (2009) investigated three different configurations of the hybrid device with rubber bumper and restrainers to prevent unseating and mitigate pounding effect at expansion joint of isolated multi-span bridges as shown in Figure 22. Recently, Shrestha, Hao and Bi (2014) evaluate the effectiveness of using rubber bumper along with two types of restrainers (SMA and steel). The authors found that the effects of the rubber bumpers on the relative joint opening displacement were not always beneficial as rubber bumpers reduce the gap width, which in turn increased the number of pounding incidences and prolonged the pounding duration although the amplitudes of pounding forces are reduced. As a consequence, the relative opening displacement at bridge joint may increase. Therefore, the authors suggested using rubber bumpers together with restrainers to mitigate the pounding damages whilst preventing deck unseating.

Figure 22. Schematic of various configuration of hybrid device at bridge expansion joint (after Abdel Raheem, 2009)

Another form of hybrid devices that have been proposed to mitigate the damages induced by the relative displacement response of bridge structures is a combination of restrainers with dampers. Zhang et al. (2009) developed a restraining damping device to control the seismic response of a benchmark base-isolated bridge. The passive control hybrid device utilized stranded superelastic CuAlBe wires as restraining/self-centering component, which not only restrain the movement but also provide good re-centering capability through their unique hysteretic behaviour at wide temperature range. As shown in Figure 23, the damper composed 
of two moving parts (denoted by block A and block B) that can slide past each other. When the dampers were subject to either tension or compression force, the CuAlBe SMA wires in one direction will be stretched. As the engagement of SMA wires would increase the stiffness of the isolated system and reduce the effectiveness of isolation, the SMA wires were designed to have a slack such that under the moderate earthquake the wires would not get engaged, and only the damping device would act. However, under larger earthquakes both the damper and SMA wires would engage to limit the movement of the bridge system.

Figure 23. Schematic of passive control hybrid damping device (after Zhang et al., 2009)

Berton, Strandgaard, and Bolander (2004) investigated the possibility of applying fluid viscous dampers along with modular expansion joints on a multi-span bridge to reduce the size of the modular expansion joint. The authors showed that for the studied case, the expansion joint size could be reduced up to the half of the size of the original design by using fluid viscous dampers. The study also showed that by using fluid viscous dampers, large girder movement could be restricted and resulting bending moment on the bridge piers could also be reduced. The hybrid solution of combining MEJ with fluid viscous dampers to mitigate the damages due to the excessive movement of bridge superstructure has found significant application in long-span bridges. Application of such hybrid device not only mitigates the seismic induced damages but also prevents the premature failures of expansion joints of long span bridges in service conditions. Recently, Guo, Liu, Zhang and Pan (2014) reported a long-term displacement monitoring from three long span steel bridges in China, the Sutong Bridge, Runyan suspension Bridge and the Jiangyin Bridge, that used MEJ and fluid viscous dampers at the joints.

\section{CONCLUSION}

The paper presents an overview of the devices used to mitigate pounding and unseating damages on bridge structures. The interest within the structural engineering community in applying these devices in retrofit of existing structures and even in new structures is evident by the rapid growth of recent researches. Based on extensive review presented in the paper, the following general conclusions are drawn.

Steel cable hinge restrainers have been traditionally used in bridge retrofit because of its low cost. However, steel restrainers rely upon the elastic strength to reduce the joint opening 
between adjacent bridge girders, which could result in large forces within the restrainers and could in turn damage the restrainers or the connected structural members. Superelastic SMA has emerged as an alternative restraining device with energy dissipating and re-centering capacity. The temperature dependence of the NiTi SMA and its high cost compared to steel bar/cable as well as the difficulty of machining large diameter bars; however, have critically limited its application. Copper based SMAs, which are relatively cheaper, easier to machine and have a wide operating temperature, have attracted attention in the recent years. Alternatively, FRP restrainers could also be used, which are easy to install and inspect.

Using devices capable of dissipating the energy could provide protection against pounding and unseating failures. However, some of these devices have no re-centering ability and are frequency dependent, which make it difficult to be control the force during the design. Moreover, some of these devices could require regular inspection. Pounding of the bridge segments could be completely precluded by the application of MEJ. However, the larger girder movement has to be accommodated, which could result in a larger bending moment at bridge piers and thus compensate the benefits of MEJ. Rubber bumpers used as shock absorbing device are effective to mitigate large impact force resulting from the pounding of adjacent girders. SMAPRs that have similar behaviour as natural rubber bumpers could be used as alternative shock absorbing device to overcome the durability problem of natural rubber bumpers.

Recent researches have focused on the application of hybrid devices that combine the advantages of two or more materials or devices to mitigate pounding and unseating damages in bridge structure. Application of rubber bumpers with restrainers, combination of dampers with the restrainers and MEJ with damping devices have received considerable attention to reduce the damages as well as improve the serviceability of the bridge.

Although, there have been significant researches on the design of restrainer devices, there are very limited works on designing the seismic restrainers considering spatially varying ground motion. As the spatial variation of earthquake ground motions are inevitable along the supports of extended structures such as long span bridges, more research focus should be provided into this. Additionally, there are limited studies on the effectiveness of these devices on the bridge with complex geometry (e.g. skewed and curved bridges). 


\section{ACKNOWLEDGEMENT}

The authors acknowledge the partial financial support from ARC Linkage project LP110200906 for carrying out this research.

\section{REFERENCES}

AASHTO (1992). Standard Specification for Highway bridges. American Association of State Highway and Transportation Officials.

Abdel-Ghaffar, S. M., Maragakis, E., Saiidi, M. (1997) Effects of the hinge restrainers on the response of the Aptos Creek Bridge during the 1989 Loma Prieta Earthquake. Earthquake Spectra, 13(2):167-189.

Andrawes, B., \& DesRoches, R. (2005). Unseating prevention for multiple frame bridges using superelastic devices. Smart Materials and Structures, 14(3), S60.

Andrawes, B., \& DesRoches, R. (2007a). Comparison between shape memory alloy seismic restrainers and other bridge retrofit devices. Journal of Bridge Engineering, 12(6), 700-709.

Andrawes, B., \& DesRoches, R. (2007b). Effect of ambient temperature on the hinge opening in bridges with shape memory alloy seismic restrainers. Engineering Structures, 29(9), 22942301.

ASTM. (2006). Standard specification for structural steel for bridges, A 709/A 709M-05. Vol. 01.04. ASTM International: West Conshohocken, PA: Annual Book of ASTM standards.

Berton, S., Strandgaard, H., \& Bolander, J. E. (2004). Effect of non-linear fluid viscous dampers on the size of expansion joints of multi-span prestressed concrete segmental boxgirder bridges. 13th World Conference on Earthquake Engineering. Canada: Vancouver, BC. Bi, K., Hao, H., \& Chouw, N. (2010). Required separation distance between decks and at abutments of a bridge crossing a canyon site to avoid seismic pounding. Earthquake Engineering \& Structural Dynamics, 39(3), 303-323.

Bi, K., Hao, H., \& Chouw, N. (2011). Influence of ground motion spatial variation, site condition and SSI on the required separation distances of bridge structures to avoid seismic pounding. Earthquake Engineering \& Structural Dynamics, 40(9), 1027-1043.

Bruneau, M., Wilson, J. C., \& Tremblay, R. (1996). Performance of steel bridges during the 1995 Hyogo-ken Nanbu (Kobe Japan) earthquake. Canadian journal of civil engineering, 23(3), 678-713. 
Caltrans, (1990) Bridge Design Specification Manual. Sacramento, CA: California Department of Transportation.

Caltrans (2008). Caltrans Bridge Design Aids, Sacramento, CA: California Department of Transportation. From http://www.dot.ca.gov/hq/esc/techpubs/manual/bridgemanuals/bridgedesign-aids/bda.html

Chang, K. C., Soong, T. T., Lai, M. L., and Nielsen, E. J. (1993). Development of a design procedure for structures with added viscoelastic dampers. ATC-17-1 Seminar on Seismic Isolation, Passive Energy Dissipation and Active Control, Vol. 2, ATC, Redwood City, California.

Chen, G., Bothe, E., \& Ger, J. (2001). Experimental characterization of metallic dampers for seismic retrofit of highway bridges. Transportation Research Record. Journal of the Transportation Research Board, (1770), 124-131.

Choi, E., Lee, D. H., \& Choei, N. Y. (2009). Shape memory alloy bending bars as seismic restrainers for bridges in seismic areas. International Journal of Steel Structures, 9(4), 261273.

Choi, E., Park, J., Yoon, S. J., Choi, D. H., \& Park, C. (2010). Comparison of seismic performance of three restrainers for multiple-span bridges using fragility analysis. Nonlinear Dynamics, 61(1-2), 83-99.

Chouw, N., \& Hao, H. (2005). Study of SSI and non-uniform ground motion effect on pounding between bridge girders. Soil Dynamics and Earthquake Engineering, 25(7), 717-728.

Chouw, N., \& Hao, H. (2008a). Significance of SSI and nonuniform near-fault ground motions in bridge response I: Effect on response with conventional expansion joint. Engineering Structures, 30(1), 141-153.

Chouw, N., \& Hao, H. (2008b). Significance of SSI and non-uniform near-fault ground motions in bridge response II: Effect on response with modular expansion joint. Engineering Structures, 30(1), 154-162.

Chouw, N., \& Hao, H. (2009). Seismic design of bridge structures with allowance for large relative girder movements to avoid pounding. Bulletin of the New Zealand Society for Earthquake Engineering, 42(2), 75.

Chouw, N., \& Hao, H. (2012). Pounding damage to buildings and bridges in the 22 February 2011 Christchurch earthquake. International Journal of Protective Structures, 3(2), 123-140. Clough, R. W., \& Penzien, J. (1975). Dynamics of structures. Mc Graw-Hill. 
Deng, K., Pan, P., Su, Y., Ran, T., \& Xue, Y. (2014). Development of an energy dissipation restrainer for bridges using a steel shear panel. Journal of Constructional Steel Research, 101, 83-95.

DesRoches, R., \& Fenves, G.L. (2000). Design of seismic cable hinge restrainers for bridges. Journal Structural Engineering ASCE, 126(4), 500-509.

DesRoches, R., \& Delemont, M. (2002). Seismic retrofit of simply supported bridges using shape memory alloys. Engineering Structures, 24(3), 325-332.

DesRoches, R., \& Muthukumar, S. (2002). Effect of pounding and restrainers on seismic response of multiple-frame bridges. Journal of Structural Engineering, 128(7), 860-869.

DesRoches, R., McCormick, J., \& Delemont, M. (2004). Cyclic properties of superelastic shape memory alloy wires and bars. Journal of Structural Engineering, 130(1), 38-46.

Earthquake Engineering Research Institute. (1999). Chi-Chi, Taiwan, Earthquake Reconnaissance Report. Report No.01-02, EERI, Oakland, California.

Elnashai, A. S., Kim, S. J., Yun, G. J., Sidarta, D. (2007). The Yogyakarta earthquake in May 27, 2006. Mid-America Earthquake Center, Report No. 07-02, Champaign, IL: The University of Illinois.

Elnashai, A. S., Gencturk, B., Kwon, O. S., Al-Qadi, I. L., Hashash, Y., Roesler, J. R., Kim, J.K., Jeong, S.H., Dukes, J. \& Valdivia, A. (2010). The Maule (Chile) earthquake of February 27, 2010: Consequence assessment and case studies. MAE Center Report No. 10-04, Champaign, IL: The University of Illinois.

Feng, M. Q., Kim, J. M., Shinozuka, M., \& Purasinghe, R. (2000). Viscoelastic dampers at expansion joints for seismic protection of bridges. Journal of Bridge Engineering, 5(1), 67-74. Guo, A., \& Li, H. (2008). Pounding reduction of highway bridges with pounding effect by using magnetorheological dampers under earthquake excitations. Advances in Structural Engineering, 11(3), 305-322.

Guo, A., Li, Z., Li, H., \& Ou, J. (2009). Experimental and analytical study on pounding reduction of base-isolated highway bridges using MR dampers. Earthquake Engineering \& Structural Dynamics, 38(11), 1307-1333.

Guo, A., Zhao, Q., \& Li, H. (2012). Experimental study of a highway bridge with shape memory alloy restrainers focusing on the mitigation of unseating and pounding. Earthquake Engineering and Engineering Vibration, 11(2), 195-204.

Guo, T., Liu, J., Zhang, Y., \& Pan, S. (2014). Displacement Monitoring and Analysis of Expansion Joints of Long-Span Steel Bridges with Viscous Dampers. Journal of Bridge Engineering, 04014099. 
Hall, F. J. (Ed.). (1994). Northridge earthquake, January 17, 1994. Earthquake Engineering Research Institute, Preliminary reconnaissance report, EERI-94-01.

Hudgings, T., Eberhard, M.O., and Stanton, J.F. (1997) Design of Seismic bridge restrainers considering spatial variation of ground motions. Report WA-RD 387.2. Washington State Transportation Center, Seattle, WA.

Ishikawa, N., Nishimoto, Y., \& Ukishima, T. (2006) Development of new bridge restrainer using laminated fiber reinforced rubber. In M. Pandey et al. (Eds.), Solid mechanics and its applications. Advances in Engineering Structures, Mechanics \& Construction. 2006; 140:809821.

Jankowski, R., Wilde, K., \& Fujino, Y. (2000). Reduction of pounding effects in elevated bridges during earthquakes. Earthquake engineering \& structural dynamics, 29(2), 195-212. Jennings, P. C. (1971). Engineering features of the San Fernando earthquake of February 9, 1971.Report EERL-71-02. Earthquake Engineering Research Laboratory, California Institute of Technology, Pasadena.

Johnson, R., Padgett, J. E., Maragakis, M. E., DesRoches, R., \& Saiidi, M. S. (2008). Large scale testing of nitinol shape memory alloy devices for retrofitting of bridges. Smart materials and structures, 17(3), 035018.

Johnson, R., Saiidi, M. S., \& Maragakis, E. M. (2006). Fiber reinforced plastics for seismic bridge restrainers. CCEER 05-2, Dept. of Civil Engineering, Univ. of Nevada, Reno, Nevada. Julian, F. D. R., Hayashikawa, T., \& Obata, T. (2007). Seismic performance of isolated curved steel viaducts equipped with deck unseating prevention cable restrainers. Journal of Constructional Steel Research, 63(2), 237-253.

Kanitkar, R., Aiken, I., Nishimoto, K., and Kasai, K. (2006). Viscoelastic dampers for the seismic retrofit of buildings: An overview of advancements in viscoelastic materials and analytical capabilities. 8th U.S. National Conf. on Earthquake Engineering, EERI, Oakland, California.

Kajita, Y., Kitahara, T., Nishimoto, Y., \& Otsuka, H. (2006, September). Estimation of maximum impact force on natural rubber during collision of two steel bars. First European Conference on Earthquake Engineering and Seismology, Geneva, Switzerland.

Kawashima, K., \& Unjoh, S. (1996). Impact of Hanshin/Awaji earthquake on seismic design and seismic strengthening of highway bridges. Structural Engineering/Earthquake Engineering JSCE 1996; 13(2):211-240. 
Kawashima, K., \& Shoji, G. (2000). Effect of restrainers to mitigate pounding between adjacent decks subjected to a strong ground motion. In Proceeding of the 12th World Conference on Earthquake Engineering, New Zealand.

Kawashima, K., Unjoh, S., Hoshikuma, J. I., \& Kosa, K. (2011). Damage of bridges due to the 2010 Maule, Chile, Earthquake. Journal of Earthquake Engineering, 15(7), 1036-1068.

Kim, J. M., Feng, M. Q., \& Shinozuka, M. (2000). Energy dissipating restrainers for highway bridges. Soil Dynamics and Earthquake Engineering, 19(1), 65-69.

Kitahara, T., Kajita, Y., Nishimoto, Y., \& Katsuki, S. (2005). Collision Test between Steel Bars with Shock Absorbing Rubber for Bridge Restrainer System using Frictionless Impact Testing Apparatus. In Proceedings of the First International Conference on Advances in Experimental Structural Engineering (pp. 901-907).

Leibovich, E., Rutenberg, A., \& Yankelevsky, D. (2012). Pounding Response of Adjacent Concrete Rods: An Experimental Study. International Journal of Protective Structures, 3(3), 355-374.

Li, B., Bi, K., Chouw, N., Butterworth, J. W., \& Hao, H. (2012). Experimental investigation of spatially varying effect of ground motions on bridge pounding. Earthquake Engineering \& Structural Dynamics, 41(14), 1959-1976.

Li, S., Mao, C., Li, H., \& Zhao, Y. (2011). Mechanical properties and theoretical modeling of self-centering shape memory alloy pseudo-rubber. Smart Materials and Structures, 20(11), 115008.

Li, S., Guo, A., Cui, L., Mao, C. \& Li, H. (2015). Pounding-induced stress wave analysis and mitigation of highway bridges under earthquakes. In Proceedings of the $11^{\text {th }}$ International conference in experimental structural engineering, University of Illinios, Urbana-Champaign. Li, Z. X., \& Yue, F. Q. (2006). Analysis and control for seismic pounding response of urban elevated bridges. 4th International conference of earthquake engineering. Taipei, Taiwan.

Lin, C. J., Hung, H., Liu, Y., \& Chai, J. (2008). Reconnaissance report of 0512 China Wenchuan earthquake on bridges. 14th World Conference on Earthquake Engineering, China. Makris, N., Roussos, Y., Whittaker, A. S., \& Kelly, J. M. (1998). Viscous heating of fluid dampers. II: Large-amplitude motions. Journal of engineering mechanics, 124(11), 12171223.

Malhotra, P. K., Huang, M. J., \& Shakal, A. F. (1995). Seismic interaction at separation joints of an instrumented concrete bridge. Earthquake Engineering \& Structural Dynamics, 24(8), 1055-1067. 
McCarthy, E., Wright, T., Padgett, J. E., DesRoches, R., \& Bradford, P. (2013). Development of an Experimentally Validated Analytical Model for Modular Bridge Expansion Joint Behaviour. Journal of Bridge Engineering, 19(2), 235-244.

Meng, Q. L., Zhang, M. Z., \& Zhou, G. L. (2011). The study on SMA Pseudo-Rubber Metal damper's control efficiency on aseismic pounding in high-pier bridge in shaking table testing. Advanced Materials Research, 163, 4429-4441.

Padgett, J. E., DesRoches, R., \& Ehlinger, R. (2010). Experimental response modification of a four-span bridge retrofit with shape memory alloys. Structural Control and Health Monitoring, 17(6), 694-708.

Padgett, J. E., \& DesRoches, R. (2013). Shape memory alloy enhanced smart expansion joint. Highway IDEA project 147, Transportation research board, The National Academies of Sciences, Engineering, and Medicine, Washington: DC.

Pan, P., Yan, H., Wang, T., Xu, P., \& Xie, Q. (2014). Development of steel dampers for bridges to allow large displacement through a vertical free mechanism. Earthquake Engineering and Engineering Vibration, 13(3), 375-388.

Polycarpou, P. C., Komodromos, P., \& Polycarpou, A. C. (2013). A nonlinear impact model for simulating the use of rubber shock absorbers for mitigating the effects of structural pounding during earthquakes. Earthquake Engineering \& Structural Dynamics, 42(1), 81-100. Polycarpou, P. C., \& Komodromos, P. (2013). Numerical Investigation of the Effectiveness of Rubber Shock-Absorbers as a Mitigation Measure for Earthquake-Induced Structural Poundings. In Computational Methods in Earthquake Engineering (pp. 417-436). Springer Netherlands.

Raheem, S. E. A. (2009). Pounding mitigation and unseating prevention at expansion joints of isolated multi-span bridges. Engineering Structures, 31(10), 2345-2356.

Ruangrassamee, A., \& Kawashima, K. (2001). Relative displacement response spectra with pounding effect. Earthquake engineering \& structural dynamics, 30(10), 1511-1538.

Ruangrassamee, A., \& Kawashima, K. (2003). Control of nonlinear bridge response with pounding effect by variable dampers. Engineering Structures, 25(5), 593-606.

Saiidi, M., Maragakis, E., Abdel-Ghaffer, S., Feng, S., \& O’Conner, D. (1993). Response of Bridge hinge resrainers during Earthquake- Field Performance, Analysis and Design. Report CCEER 93/06, Center for Civil Engineering and Earthquake Research, University of Nevada, Reno.

Saiidi, M., Randall, M., Maragakis, E., \& Isakovic, T. (2001). Seismic restrainer design methods for simply supported bridges. Journal of Bridge Engineering, 6(5), 307-315. 
Saiidi, M. S., Johnson, R., \& Maragakis, E. M. (2006). Development, shake table testing, and design of FRP seismic restrainers. Journal of Bridge Engineering, 11(4), 499-506.

Selna, L.G., Malvar, L.J., \& Zelinski, R.J. (1989). Bridge retrofit testing: hinge cable restrainer. Journal of Structural Engineering, 155(4), 920-934.

Sheikh, M. N., Xiong, J., \& Li. W. H. (2012) Reduction of seismic pounding effects of baseisolated RC highway bridges using MR damper. Structural Engineering and Mechanics 41(6), 791-803.

Shinozuka, M., Feng, M. Q., Kim, J. M., Nagashima, F., \& Kim, H. (2000, April). Mitigation of seismic pounding effect on bridges using dynamic restrainers. In SPIE's 7th Annual International Symposium on Smart Structures and Materials (pp. 377-387). International Society for Optics and Photonics.

Shrestha, B., Hao, H., \& Bi, K. (2014). Effectiveness of using rubber bumper and restrainer on mitigating pounding and unseating damage of bridge structures subjected to spatially varying ground motions. Engineering Structures, 79, 195-210.

Shrestha, B., Hao, H., \& Bi, K. (2015). Seismic Response Analysis of Multiple-Frame Bridges with Unseating Restrainers Considering Ground Motion Spatial Variation and SSI. Advances in Structural Engineering, 18(6), 873-892.

Shrestha, B., \& Hao, H. (2015). Parametric study of seismic performance of super-elastic shape memory alloy-reinforced bridge piers. Structure and Infrastructure Engineering, 1-14.

Soong, T. T., \& Dargush, G.F. (1997) Passive energy dissipation systems in structural engineering. Wiley, London.

Strandgaard, H. (2000, April). Design and application of energy-dissipating dampers on a new concrete bridge in California. In SPIE's 7th Annual International Symposium on Smart Structures and Materials (pp. 400-411). International Society for Optics and Photonics.

Symans, M. D., Charney, F. A., Whittaker, A. S., Constantinou, M. C., Kircher, C. A., Johnson, M. W., \& McNamara, R. J. (2008). Energy dissipation systems for seismic applications: current practice and recent developments. Journal of Structural Engineering, 134(1), 3-21.

Trochalakis. P., Eberhard. M.O., \& Stanton, J.F. (1997). Design of seismic restrainers for inspan hinges. Journal of Structural Engineering ASCE, 123(4), 469-478.

Vasseghi, A. (2011). Energy dissipating shear key for precast concrete girder bridges. Scientia Iranica, 18(3), 296-303.

Vlassis, A. G., Maragakis, E., \& Saiidi, M. (2004). Experimental evaluation of longitudinal seismic performance of bridge restrainers at in-span hinges. Journal of Testing and Evaluation, 32(2), 96-105. 
Watanabe, G., \& Kawashima, K. (2004). Effectiveness of cable-restrainer for mitigating rotation of a skewed bridge subjected to strong ground shaking. 13th World Conference on Earthquake Engineering, New Zealand.

Yang, C. S. W., \& DesRoches, R. (2015). Bridges with Innovative Buckling Restrained SMA Expansion Joints Having a High Symmetrical Tension/Compression Capacity. Structures Congress 2015, 452-461.

Zhang, Y., Hu, X., \& Zhu, S. (2009). Seismic performance of benchmark base-isolated bridges with superelastic $\mathrm{Cu}-\mathrm{Al}-\mathrm{Be}$ restraining damping device. Structural Control \& Health Monitoring, 16, 668-685.

Zhu, P., Abe, M., \& Fujino, Y. (2004) Evaluation of pounding countermeasures and serviceability of elevated bridges during seismic excitation using 3D modelling. Earthquake engineering \& structural dynamics, 33(5), 591-609. 


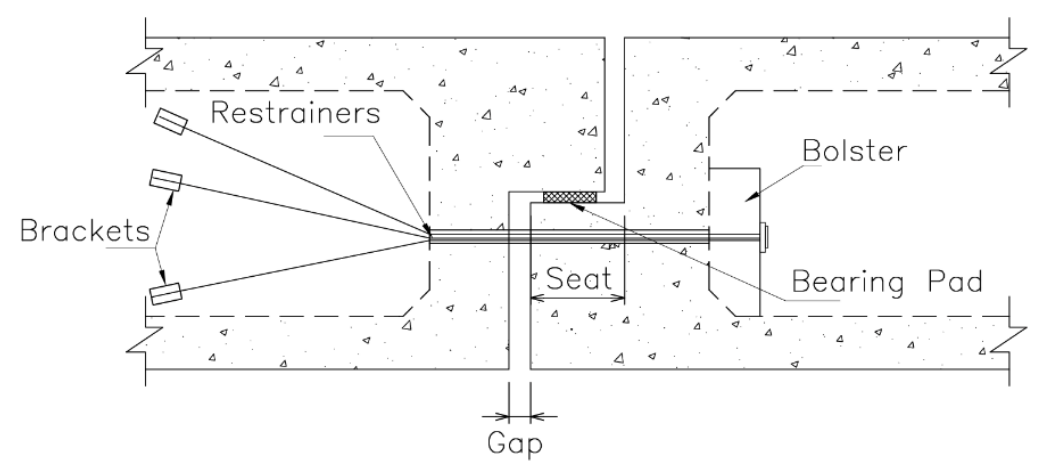

Figure 1. Hinge restrainer retrofit scheme.

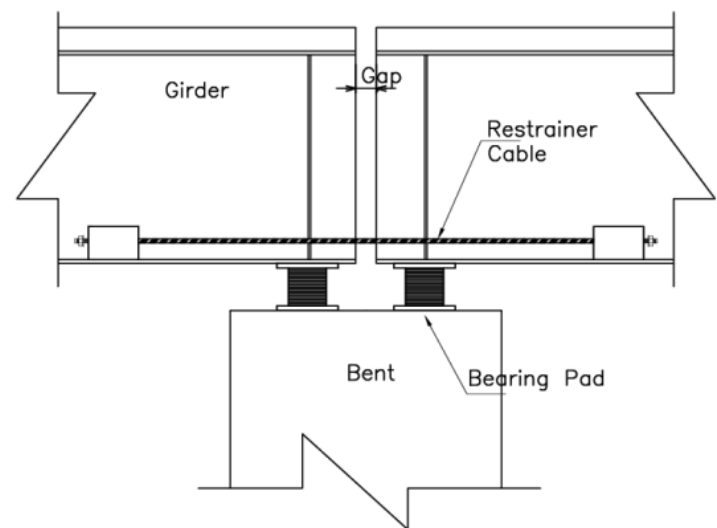

(a)

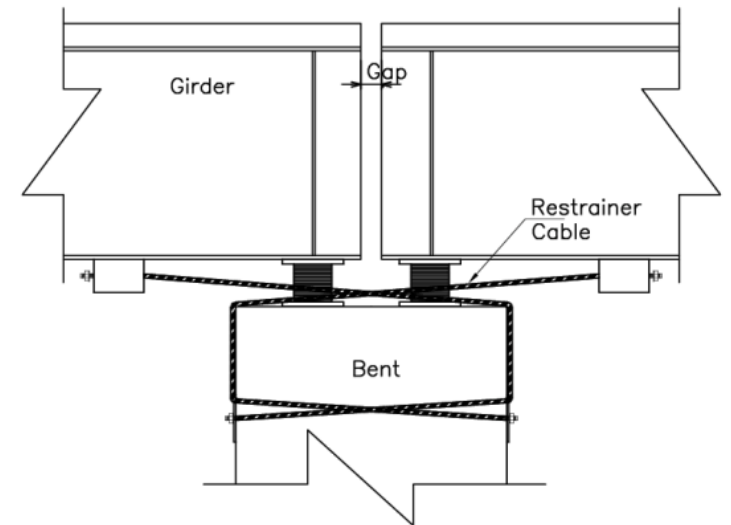

(b)

Figure 2. (a) Girder to girder and (b) girder to column restrainer attachment for simply supported bridges.

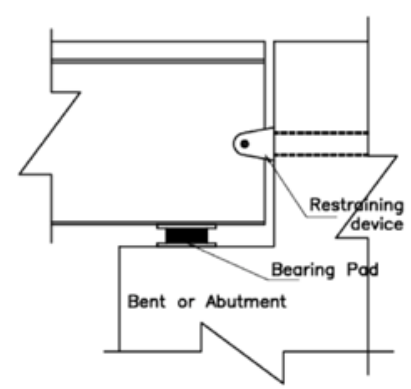

(a)

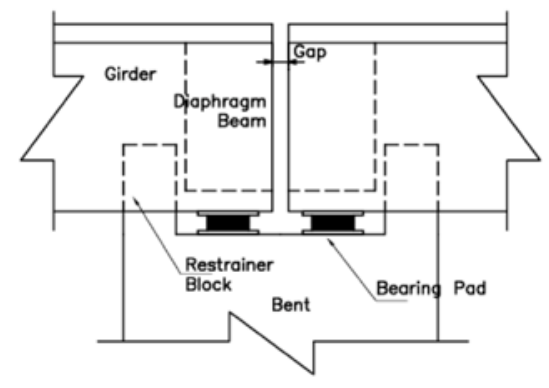

(b)

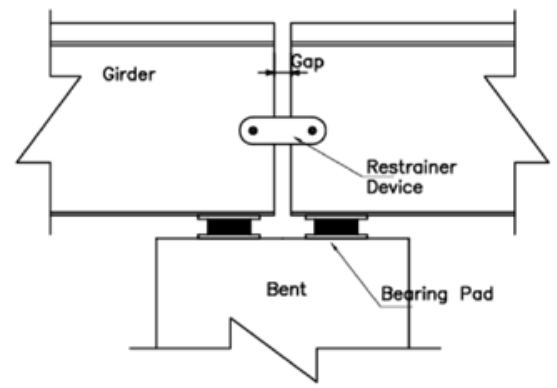

(c)

Figure 3. Japanese displacement restriction devices. 

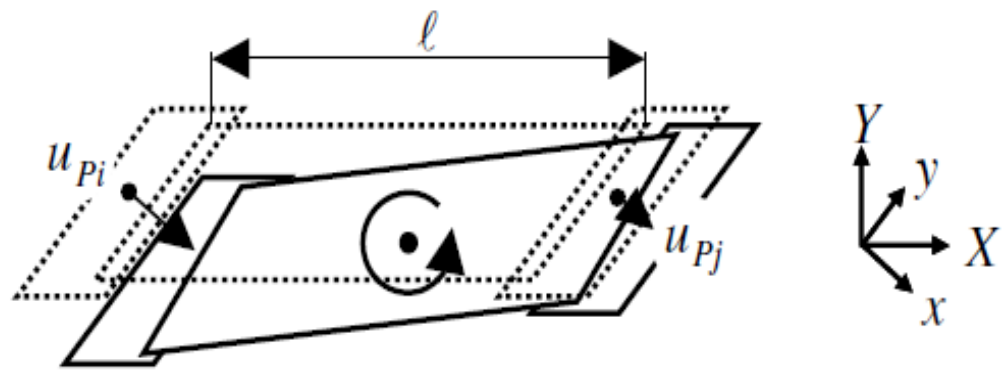

Figure 4. Skew bridge rotation due to incoherent response (after Watanabe and Kawashima 2004).

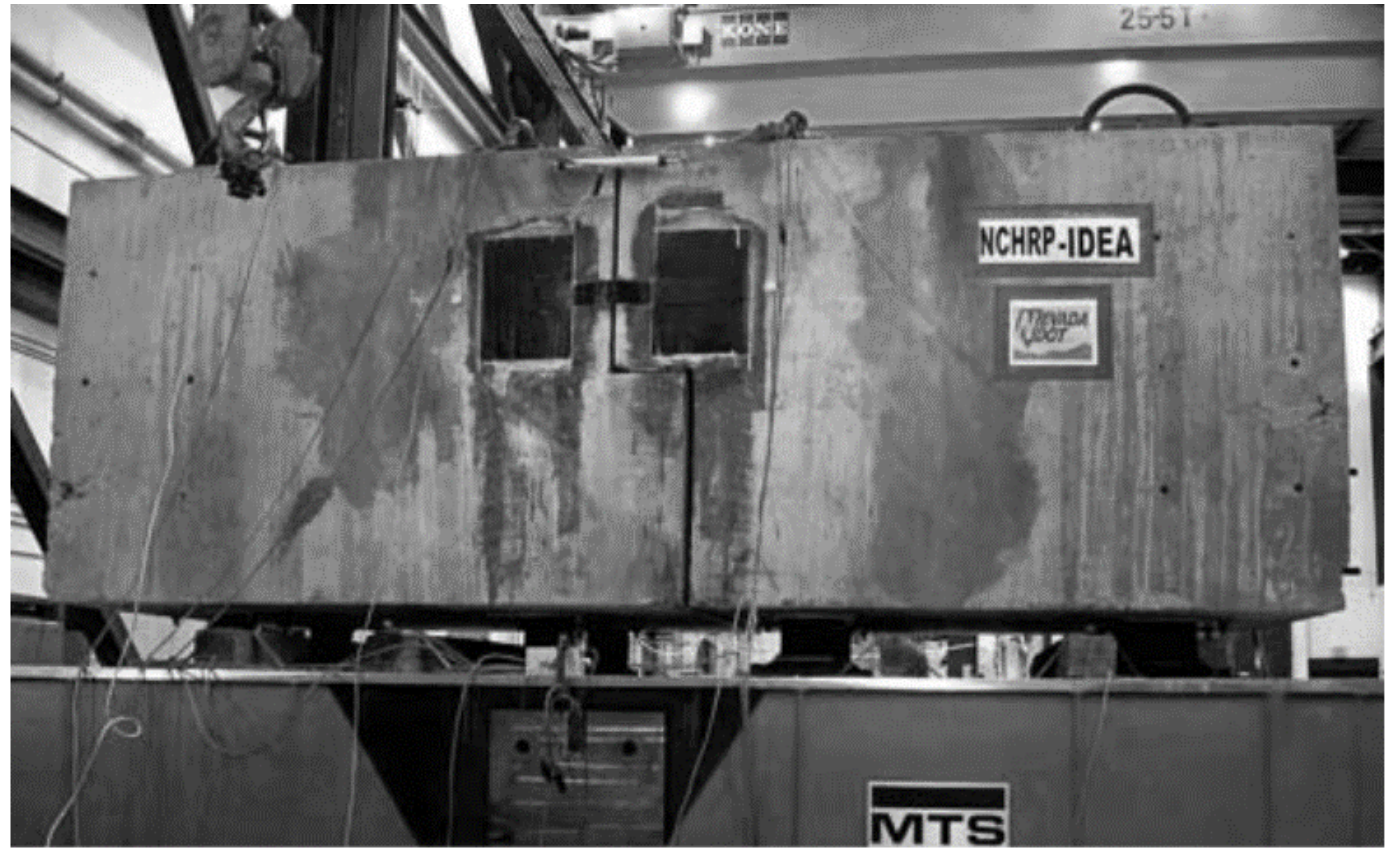

Figure 5. Test setup for CFRP restrainer (after Johnson et al. 2005) 


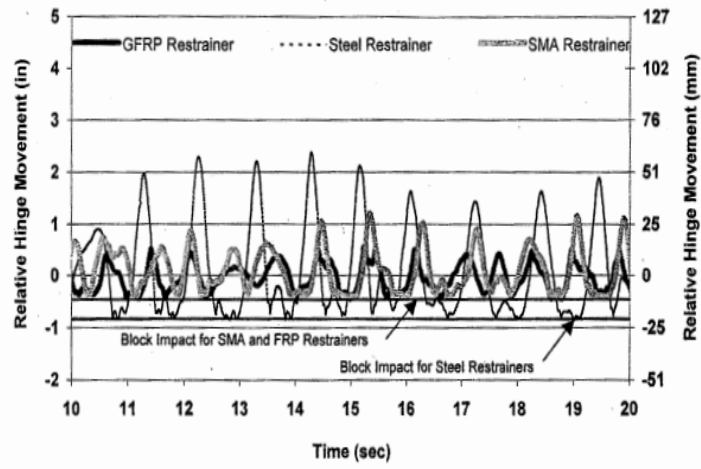

(a)

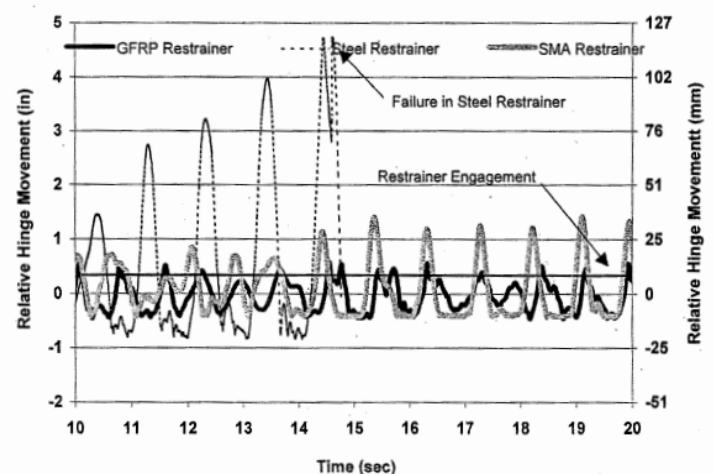

(b)

Figure 6. Comparison of hinge movement (a); superstructure acceleration for different restrainer types (after Johnson et al. 2005)
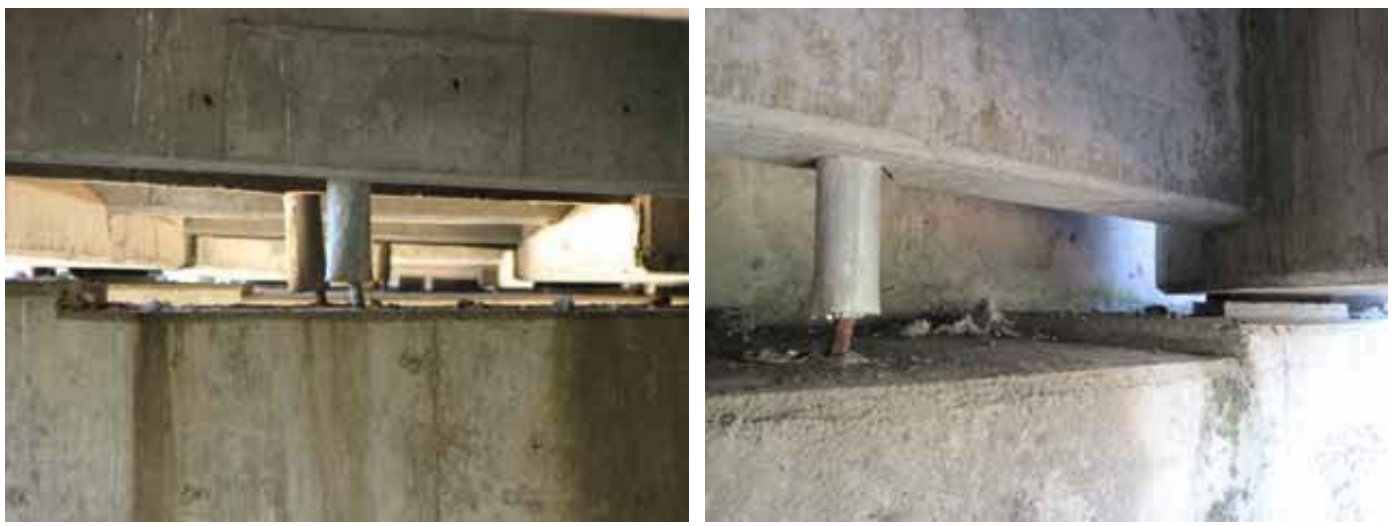

Figure 7. Metallic yielding dampers on Chilean bridges (after Elnashai et al. 2010)

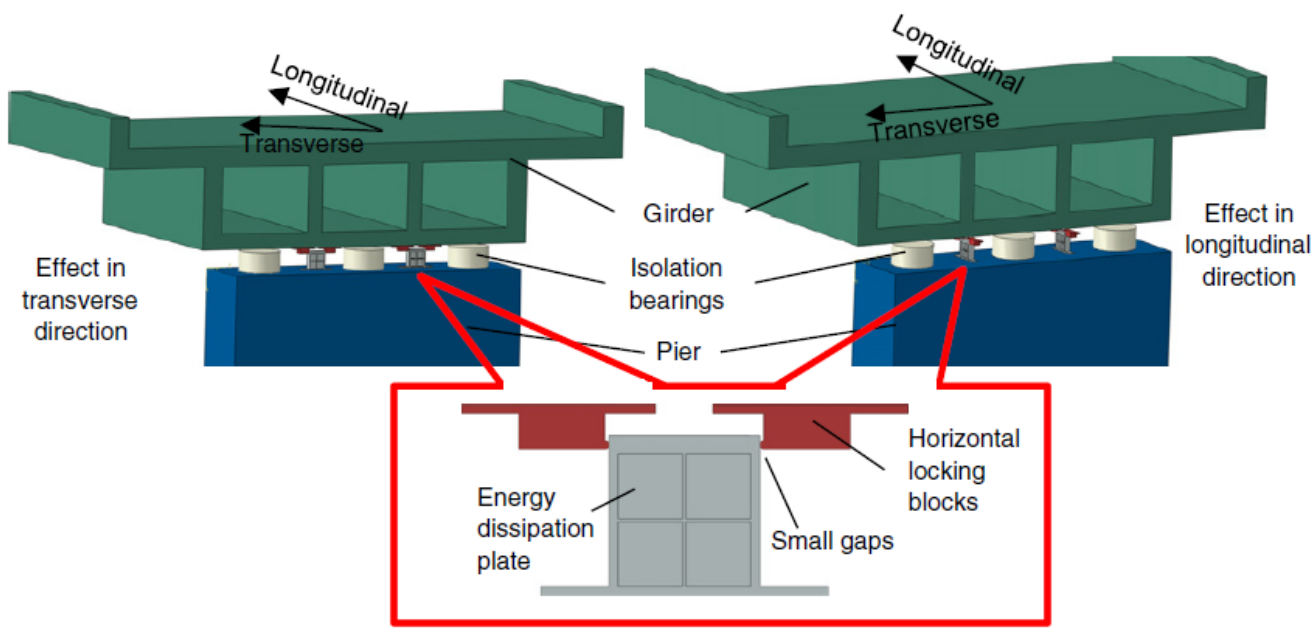

Figure 8. Installation of the device (after Deng et al. 2014) 


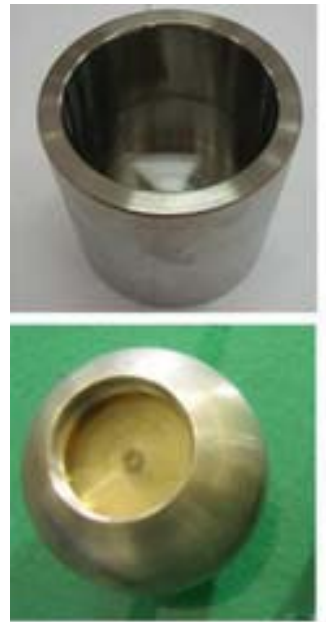

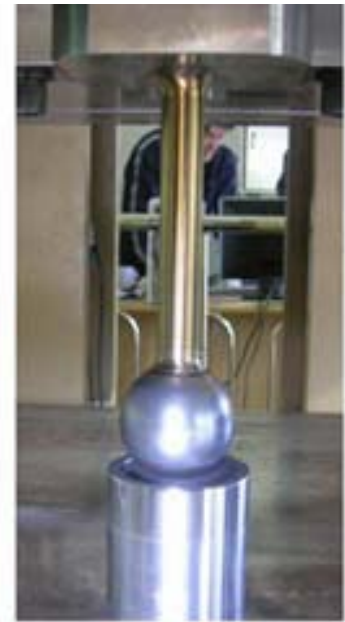

(a)

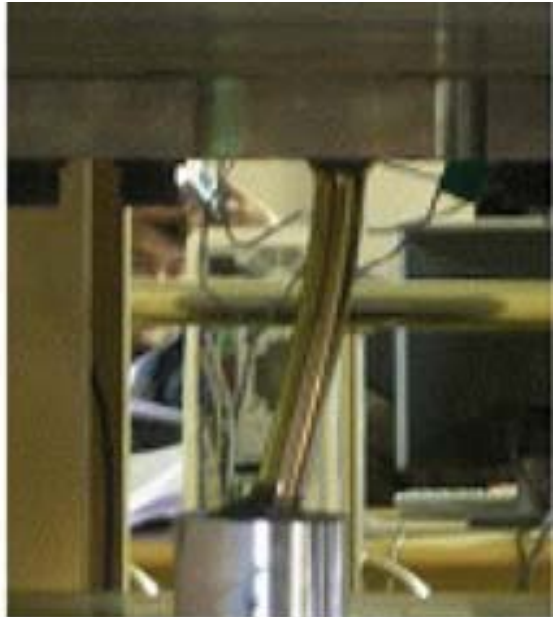

(b)

Figure 9. Test setup for SMA bar under single bending; (a) a ball and a cylinder; (b) a ball bolted to the SMA bar and the cylinder welded at the bottom; (c) bending shape of SMA bar under single bending (after Choi et al. 2009)
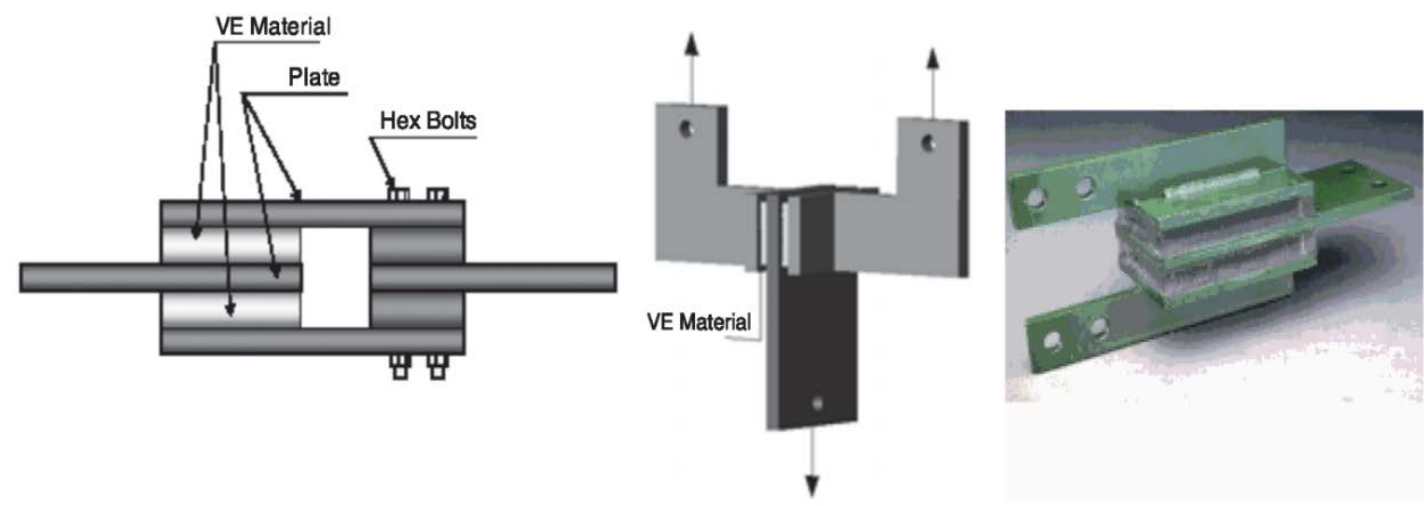

Figure 10. Typical viscoelastic Dampers. 


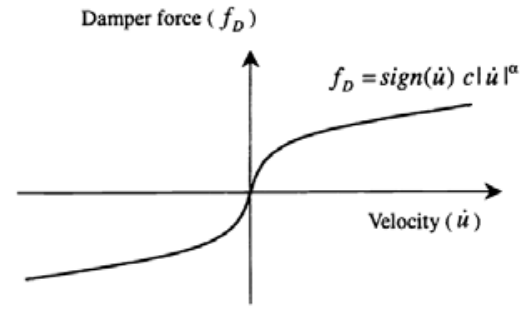

(a)

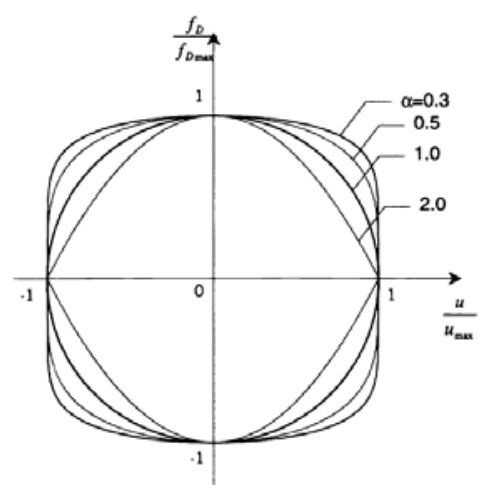

(b)

Figure 21. (a) Force-velocity relation for dampers with varying value of $\alpha$, (b) Hysteresis loop of a viscous damper for different value of $\alpha$

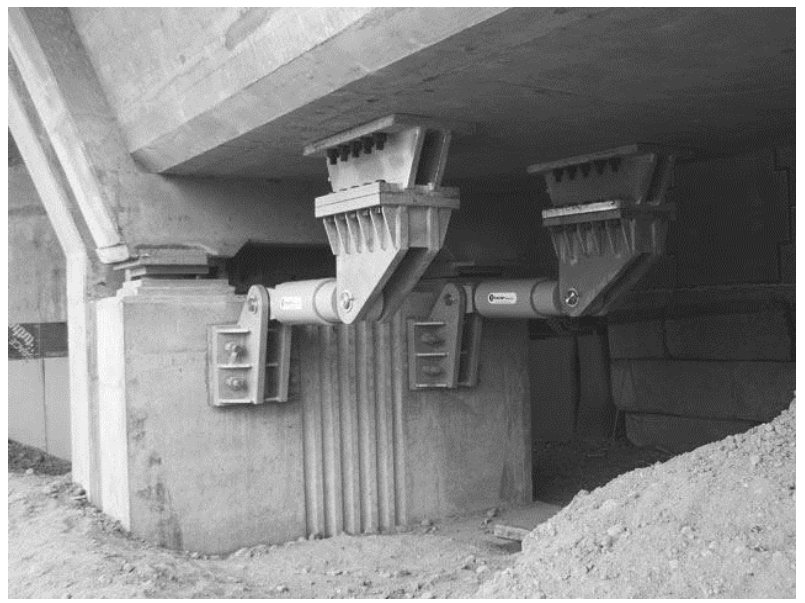

Figure 12. Shock transmission unit installed in a bridge.

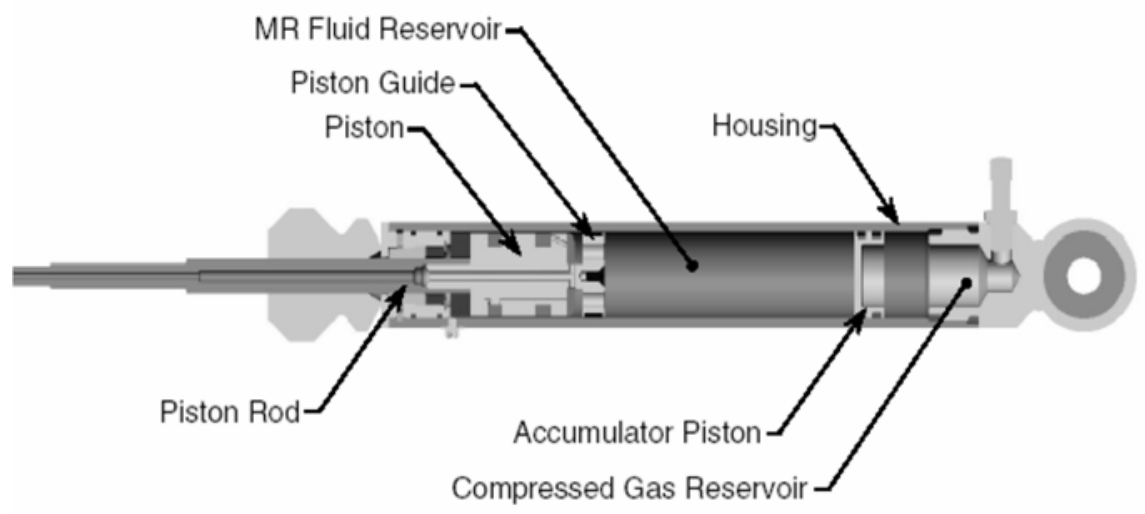

Figure 13. Mono-tube MR damper section view 

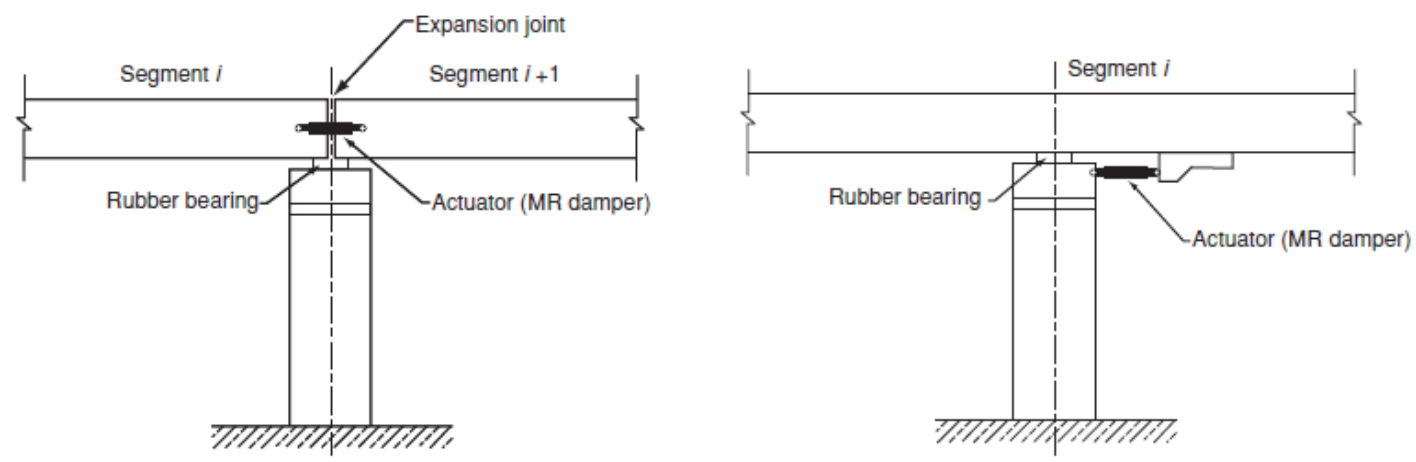

Figure 14. The installation schemes of the control devices (after Guo \& Li, 2008)

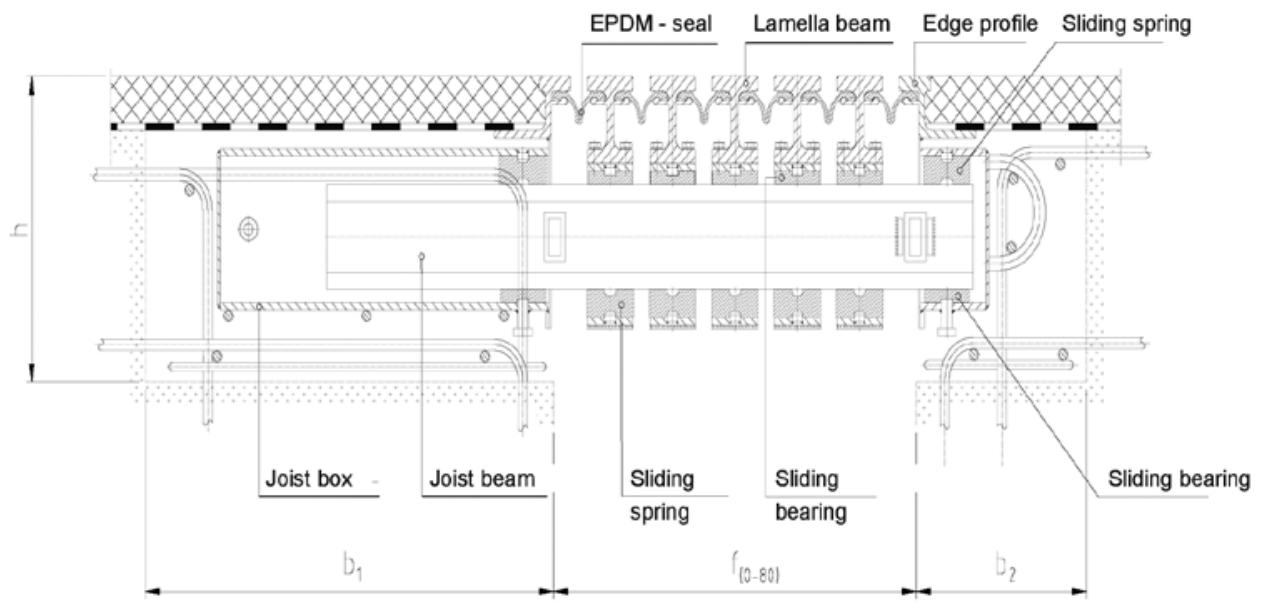

Figure 15. Section view of modular expansion joint

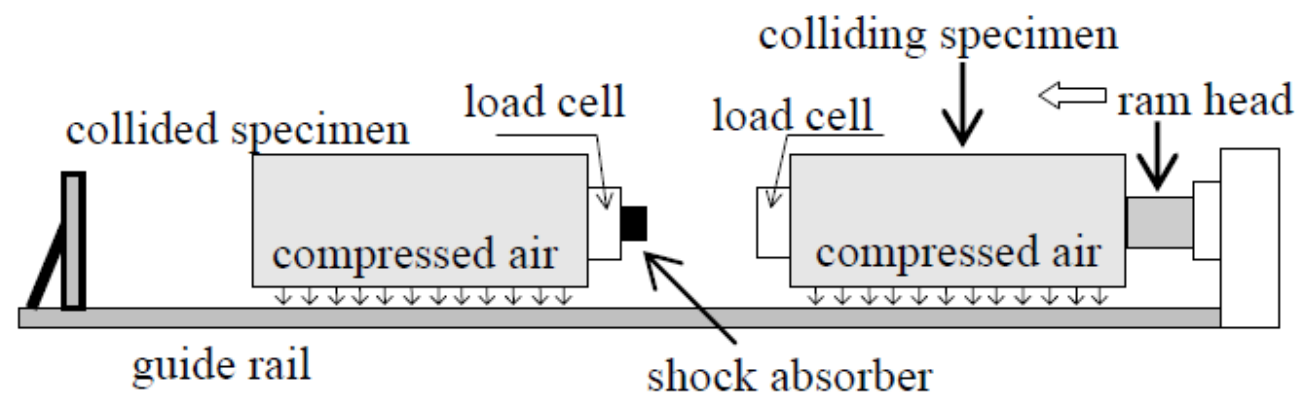

Figure 16. Test setup for the collision test of rubber bumper (after Kajita et. al. 2006) 


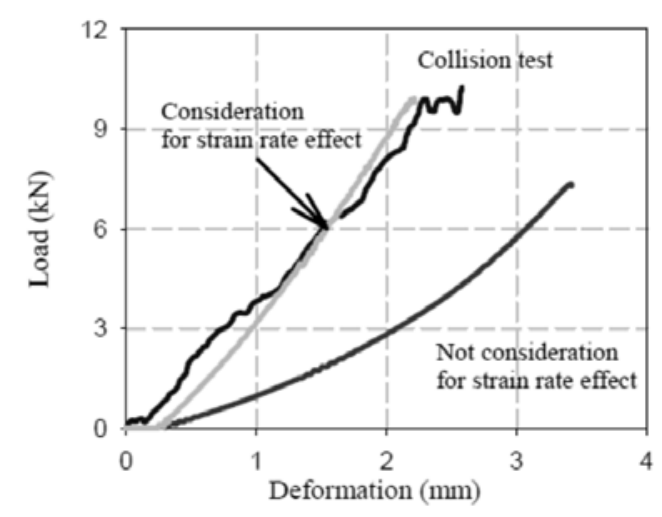

(a)

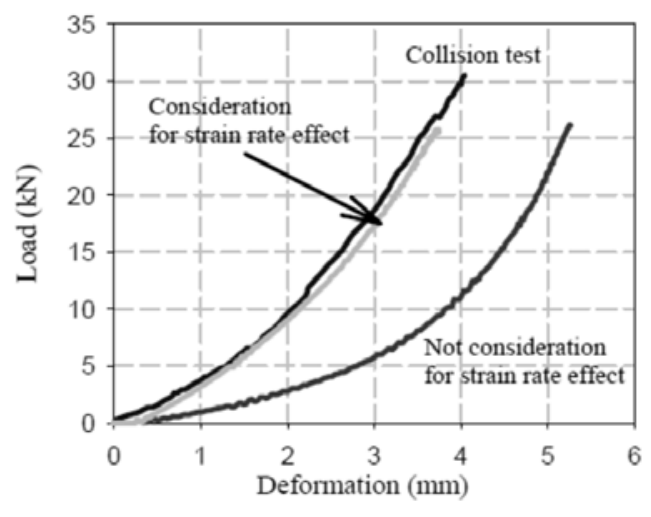

(b)

Figure 17. Load vs Deformation curve with and without consideration of strain rate effect at $\mathrm{v}=0.34 \mathrm{~m} / \mathrm{s}$ (left); and $\mathrm{v}=0.68 \mathrm{~m} / \mathrm{s}$ (right) (after Kajita et. al. 2006)

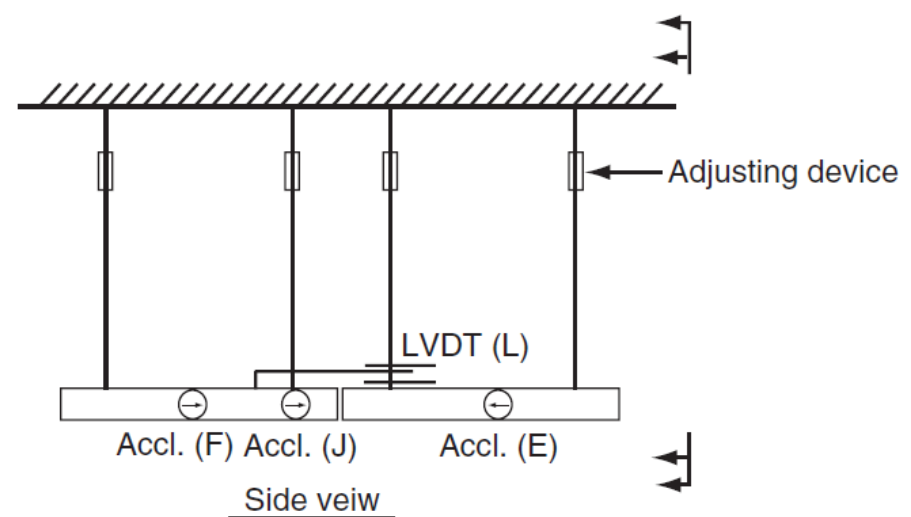

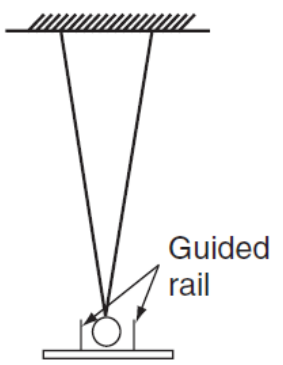

Section 1-1

Figure 18. Experimental setup for impact test (after Leibovich et. al. 2012)

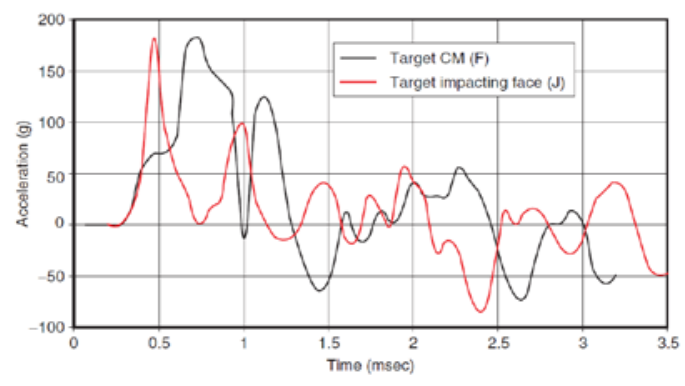

(a)

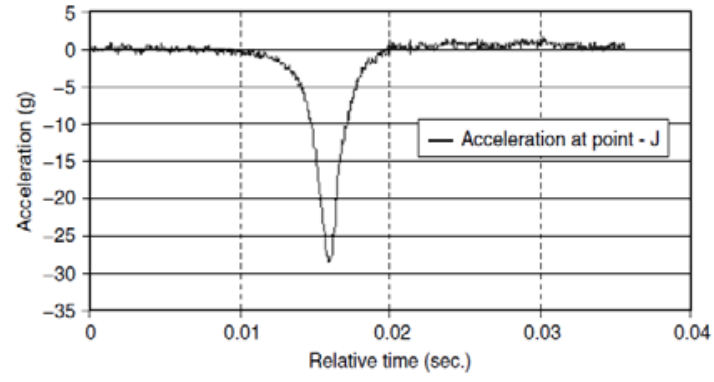

(b)

Figure 19. Acceleration record of concrete pile impact (a) without shock absorbing device, (b) with shock absorbing device (after Leibovich et. al. 2012) 

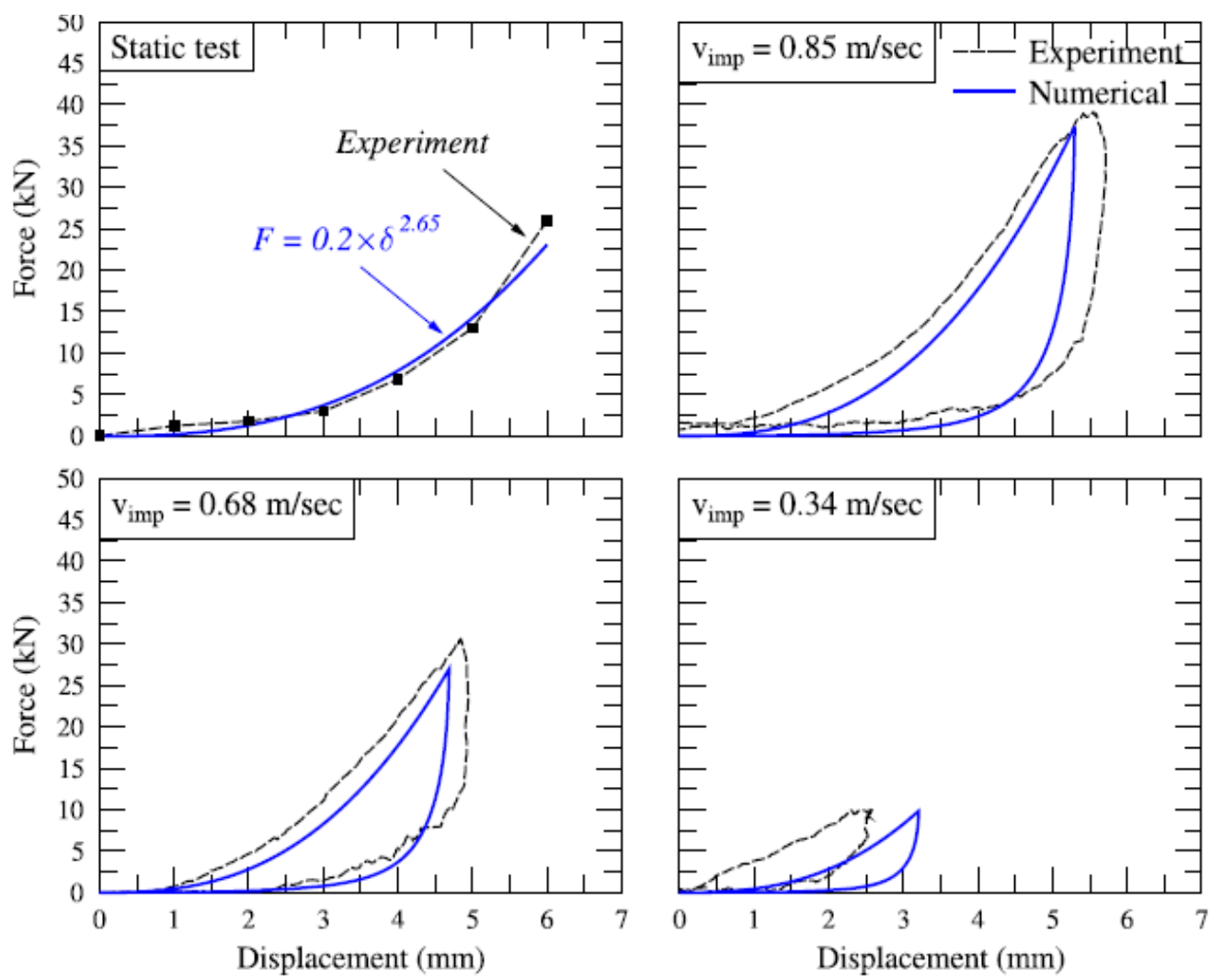

Figure 20. Comparison between experimental and numerical force-displacement diagrams of a $10 \mathrm{~mm}$ thick rubber shock absorber for static and dynamic tests (after Polycarpou \& Komodromos 2013a)

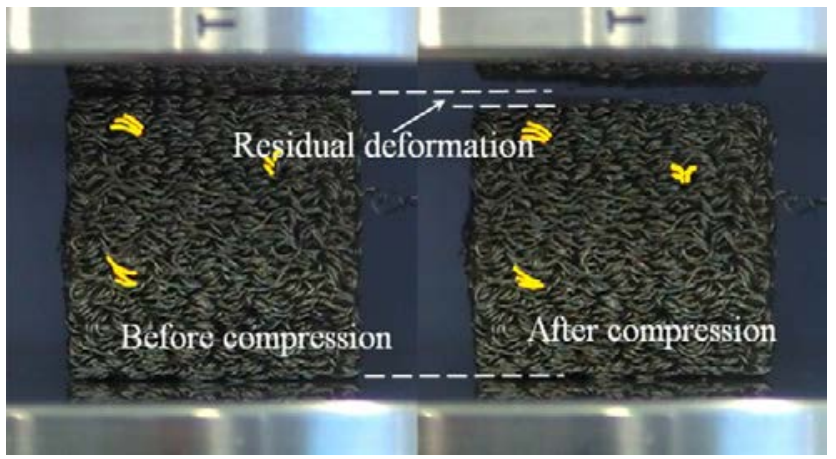

(a)

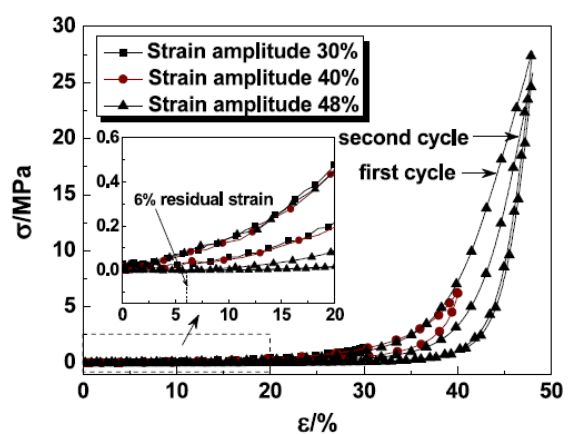

(b)

Figure 21. Self-restorable strain for SMAPR specimen (after Li et al. 2011) 

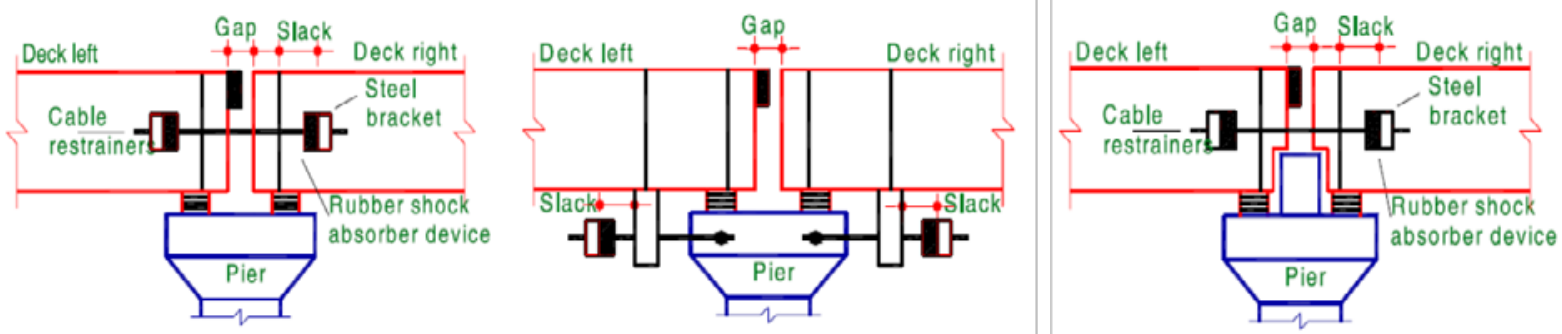

Figure 22. Schematic of various configuration of hybrid device at bridge expansion joint

(after Abdel Raheem, 2009)

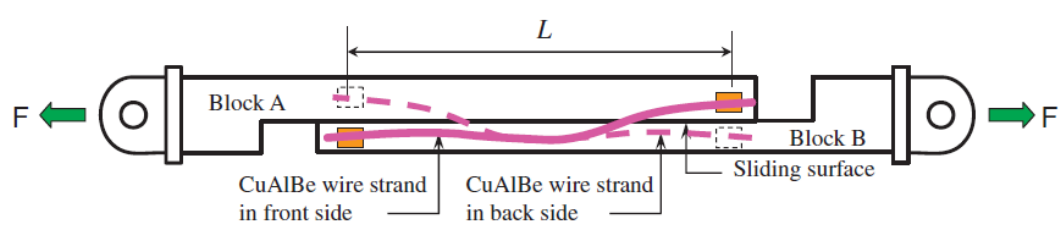

Figure 23. Schematic of passive control hybrid damping device (after Zhang et al. 2009) 